\title{
Las disparidades interprovinciales en Boyacá
}

EDILBERTO RODRÍGUEZ ARAÚJO

Profesor Escuela Economía UPTC

Fecha de recepción: 30 de abril de 2007

Fecha de aprobación: 05 de junio de 2007 


\section{RESUMEN:}

Similar a lo que ocurre entre los diferentes departamentos y/o regiones colombianas, entre las distintas provincias de Boyacá se observa una cre ciente disparidad socio demográfica y económica. El desequilibrio en el desarrollo provincial se deriva de la heterogeneidad estructural y requiere de políticas muy puntuales que reduzcan las brechas existentes.

Palabras clave: provincia, disparidad, desarrollo, políticas, equilibrio re gional.

\section{ABSTRACT:}

As it occurs in different Colombian departments and/or regions, among the different provinces of Boyacá a growing socio demographic and economic inequality can be observed. The unbalance in the provincial development derives from structural heterogeneity and requires very punctual policies to reduce the existing gaps.

Key words: Province, inequality, development, policies, regional balance. 


\section{Introducción}

La actual configuración políticoadministrativa del país ha privilegiado figuras decimonónicas como el municipio y el departamento, y menos emergentes figuras como la provincia y la región, con una tradición intermitente, particularmente la primera. El desarrollo regional del país ha sido desequilibrado. Las políticas que se adoptaron en el siglo pasado para encauzarlo tuvieron un sesgo sectorialista o circunscrito a la corrección de problemas (Rodríguez, 2007) derivados de desastres naturales o del conflicto interno.

El análisis de las desigualdades interprovinciales ha sido poco abordado en la literatura sobre desarrollo regional, quizá porque esta figura de la orga- nización territorial no se arraigó en todos los departamentos del país. Boyacá es uno de los departamentos donde la provincia se ha arraigado en el imaginario colectivo, a pesar de que su desarrollo ha sido trunco.

Este ensayo busca examinar la trayectoria reciente del desarrollo provincial, identificando las fuerzas centrípetas que han inducido su fortalecimiento o prematura decadencia.

\section{Los orígenes de la provincia colombiana}

La provincia como entidad político administrativa se remonta al Imperio Romano y se arraigó en Colombia, a través de instituciones coloniales, como las Gobernaciones de las que se derivaron las provincias que se asentaron en los 
centros urbanos de mayor relevancia en el territorio nacional.

Entre 1717 y 1810 el Virreinato de la Nueva Granada contó con 24 provincias, subdivididas en cantones y parroquias. Después de la gesta independentista, el incipiente Estado Nacional adquirió el nombre Confederación de Provincias Unidas de la Nueva Granada (18101819), constituido por 15 provincias. Posteriormente, transcurrido el periodo de la Gran Colombia (1819-1830) ${ }^{1}$ -en 1824 existían 12 departamentos y 38 provincias, además de cantones y parroquias-, la provincia mantuvo un notorio protagonismo, con el surgimiento de la República de la Nueva Granada (1830-1856), suprimiéndose los departamentos existentes y fortaleciéndose las provincias (19), que junto a los distritos parroquiales, anteriormente parroquias, constituían la estructura básica de la organización territorial colombiana.

Entre $1857^{2}$ y $1863^{3}$ opera la Confederación Granadina que restablece los Estados soberanos, integrados por provincias y distritos parroquiales, que son suprimidos en $1886^{4}$, bajo la presidencia de Rafael Núñez, finalizando así los ensayos federalistas, iniciados en 1863 cuando se instauraron los Estados Unidos de Colombia, conformados por nueve Estados soberanos. Rafael Núñez implantó una férrea centralización política, preservando la descentralización administrativa.

La aparición de los departamentos -en 1904 se contaban 25 que, posteriormente, se redujeron a 9 y luego se "sobreexpandieron", tal como se le conoce actualmente- fue un intento de sofocar las provincias históricas y someterlas al control del gobierno central. Los municipios como eslabón de la división político-administrativa se remontan a 1936. La provincia se esfuma del escenario territorial.

En la Constitución de 1886, con su impronta centralista, la figura de la provincia fue desplazada por la de departamento; como un nivel subordinado, con restringidas competencias funcionales. Despuntando el siglo XX -luego que en el gobierno del general Rafael Reyes se exhibiera una actitud ambivalente hacia su permanencia (en 1905 existían 95 provincias y 34 departamentos, Fals, 1996)-, entre 1936 y 1945, se entronizaron como figuras centrales los municipios y los departamentos, perdiendo in-

1 En 1821 en el Congreso de Cúcuta surgió el departamento de Boyacá. Los departamentos estuvieron acompañados de figuras como las provincias, los cantones y las parroquias. El departamento de Boyacá estaba integrado por las provincias de Tunja, Pamplona, Socorro y Casanare.

2 En 1857 el Estado soberano de Boyacá estaba conformado por las provincias de Tunja, Tundama y Casanare y los cantones de Chiquinquirá y Vélez.

3 De los cuatro departamentos existentes en 1857 se pasó a seis en 1863: Casanare, Tundama, Norte, Occidente, Oriente y Centro.

4 La actual organización territorial proviene de la Constitución de 1886: con las tres entidades básicas: departamentos, provincias y municipios. 
cidencia real las provincias, las que fueron suprimidas del ordenamiento jurídico en $1945^{5}$, resurgiendo sólo en 1991 con la promulgación de la nueva Constitución Política $^{6}$, la que estableció la posibilidad de crearse (artículo 321) por iniciativa de gobernadores y alcaldes.

La Constitución de 1991 circunscribiría las posibilidades de creación de regiones, en el marco de la asociatividad territorial de municipios contiguos, a instancias de cooperación inter y supramunicipal -distinta a las áreas metropolitanas- para la prestación de servicios públicos y proyectos infraestructurales y ambientales, tendiente a la reducción de los desequilibrios socioeconómicos y ambientales ${ }^{7}$. La exploración de sinergias en los diferentes niveles de la organización territorial contribuirá a reforzar su cohesión y cooperación, reafirmando sus complementariedades funcionales.

El arraigo de la provincia se evidencia en la permanencia de la figura provincial o su equivalente (distritos, subregiones, etc.) en departamentos como Caldas (6), Cauca (5), Antioquia (9), Cundinamarca (15), Bolivar (6), Santander (6), entre otros; en tanto que en Boyacá las 13 provincias están ancladas en el imaginario colectivo, como un referente de autoidentidad territorial que imprime pertenencia cultural a los pobladores de estas. La actual configuración tiene como antecedente la Ordenanza 037 de 1991 que apalancó la asociación de los 123 municipios de Boyacá, determinando unas pautas organizacionales para propiciar un adecuado funcionamiento, propósito que no se logró.

En Colombia el ordenamiento territorial ha respondido a móviles coyunturales de quienes detentaban el poder político, reduciendo el ordenamiento a un arbitrario artificio institucional, a una "división territorial” como se le denominó a lo largo del siglo XX, con desconocimiento de las raíces históricas y los lazos culturales en la autodeterminación de los pueblos.

La Constitución de 1991, revalidando los procesos de descentralización y

\footnotetext{
$\overline{5}$ En 1911 se produjo la primera intentona de liquidar las provincias.

6 En el Título XI, Capítulo 1, "De las disposiciones generales", el artículo 286 prescribe: "Son entidades territoriales los departamentos, los distritos, los municipios y los territorios indígenas.

La ley podrá darles el carácter de entidades territoriales a las regiones y provincias que se constituyan en los términos de la Constitución y la ley". De otra parte, el capítulo 3, "Del régimen municipal", en el artículo 321, manifiesta: "Las provincias se constituyen con municipios o territorios indígenas circunvecinos, pertenecientes a un mismo departamento".

7 "Las provincias son entidades territoriales conformadas por un número plural de municipios y/o entidades territoriales indígenas circunvecinas pertenecientes a un mismo departamento, para impulsar proyectos de interés subregional de desarrollo económico, social y ambiental". Véase Ordenamiento territorial colombiano y el marco normativo, Oswaldo Porras et al, Departamento nacional de Planeación, Dirección de Desarrollo Territorial, p. 12. Las propuestas presentadas en los últimos años precisan que antes de convertirse en provincia territorial debe implantarse provincia administrativa y de planificación por un término mínimo de seis años.
} 
autonomía territorial, sólo reconoció cuatro figuras de entidades territoriales: el departamento, el municipio, el distrito y las entidades Territoriales Indígenas (ETIs), previendo la creación de la provincia y la región. Orlando Fals Borda, Secretario General de la extinta Comisión de Ordenamiento Territorial (COT), entre los años 1991 y 1994, anota: "Una de esas figuras, propia nuestra así provenga de la época colonial, es la Provincia, concebida como unión de varios municipios afines y colindantes, que trabajan juntos, producen juntos, se conocen y apoyan unos a otros", agregando: "Colombia nació como unión de Provincias, no de departamentos. El primer nombre de nuestro país fue Provincias Unidas de Nueva Granada, y la provincia ha seguido viva en muchas partes del país” (Fals, 2001: 21) ${ }^{8}$.

Pese a que la Constitución Nacional fijó la urgencia de expedir la Ley Orgánica de Ordenamiento Territorial (LOOT), esta ha sido una frustración nacional, pues más de una decena de proyectos han sucumbido ante la inercia parlamentaria, ante la persistencia de las tensiones y los conflictos territoriales.

Andrés de Zubiría, refiriéndose a la figura de la provincia -que como la de región ha sido un proyecto societal fallido- señala: "simplemente establecen como división o entidad administrativa, sin funciones propias (sólo actúa por delegación del nivel nacional o departamental, o por designación de competencias por parte de los municipios y/o los territorios indígenas miembros), como implementación de la figura de la 'desconcetración' de funciones del nivel departamental y, lo más controvertible, buscando impedir la posibilidad de que luego de creada una provincia como ente administrativo, se pueda convertir en entidad territorial, lo que implicaría: autogobierno, autoadministración, recursos propios y transferencias, es decir, formar parte del nuevo mapa territorial por construir en Colombia” (De Zubiría, 1994:125).

\section{Caracterización de la econo- mía departamental}

$\mathrm{Al}$ analizar las cifras de las Cuentas Departamentales (Dane), del periodo 1990-2005, se constata una tendencia análoga a la encontrada por el Centro de Estudios Ganaderos (Cega, 2004, 2006): la participación del PIB departamental nominal declinó, al reducirse de 2,79 a 2,41\%, siendo el año en que la cota fue superior, 1993 (3,09\%). En términos reales, la pérdida de peso relati-

\footnotetext{
Orlando Fals, contrario a la existencia de los departamentos, por considerarlos redundantes, escribe: "Los pivotes principales del autonomismo unitario que consagra la Constitución son las Provincias (constituidas por Municipios afines) y las regiones, no los Departamentos", puntualizando: "El establecimiento de las Provincias y las Regiones como unidades territoriales será una contribución a la paz y al progreso porque articulan una visión macro ayudando a resolver problemas mayores que inciden en los conflictos, y que los municipios y departamentos solo son incapaces de resolver". Véase "Guía del ordenamiento territorial en Colombia: contribución para la solución de conflictos", Análisis Político, No. 36, enero-abril, 1999, IEPRI, p.87.
} 
vo fue acentuada, al saltar de 2,95\% en 1990 a 2,41\% en el 2005. El año en que el nivel fue más elevado fue 1993 (3,10\%).

La trayectoria seguida por la economía departamental fue espasmódica, cíclica, lo que no anticipa ningún crecimiento sostenido. Salvo algunos años, la eco- nomía nacional creció a un ritmo superior a la economía departamental. Resulta ilustrativo de ese comportamiento fluctuante el hecho que el año 1999, punto de flexión de la economía colombiana, cuando esta colapsó $(-4,20 \%)$, la economía boyacense obtuvo un modesto crecimiento $(0,37 \%)$, lo que evidencia tendencias divergentes.

Cuadro No. 1

Evolución de la economía departamental (\%)

\begin{tabular}{|c|c|c|c|}
\hline AÑO & $\begin{array}{c}\text { PARTICIPACIÓN PIB REAL } \\
\text { BOYACÁ/PIB REAL NACIONAL }\end{array}$ & $\begin{array}{c}\text { VARIACIÓN PIB REAL } \\
\text { COLOMBIA }\end{array}$ & $\begin{array}{c}\text { VARIACIÓN PIB REAL } \\
\text { BOYACÁ }\end{array}$ \\
\hline 1990 & 2,95 & - & - \\
1991 & 2,92 & 2,37 & 1,37 \\
1992 & 2,86 & 4,35 & 2,18 \\
1993 & 3,10 & 5,71 & 14,57 \\
1994 & 2,81 & 5,15 & $-4,58$ \\
1995 & 2,71 & 5,20 & 1,51 \\
1996 & 2,57 & 2,06 & $-3,28$ \\
1997 & 2,55 & 3,43 & 2,66 \\
1998 & 2,42 & 0,57 & $-4,52$ \\
1999 & 2,54 & $-4,20$ & 0.37 \\
2000 & 2,56 & 2,92 & 3,68 \\
2001 & 2,57 & 1,47 & 1,79 \\
2002 & 2,46 & 1,93 & $-2,47$ \\
2003 & 2,56 & 3,86 & 8,30 \\
2004 & 2,42 & 4,87 & $-0,92$ \\
2005 & 2,41 & 4,72 & 4,20 \\
\hline
\end{tabular}

Fuente: Dane, Cuentas Regionales.

Al hacerse un corte transversal de la trayectoria del PIB, se encontrará que el periodo más crítico fue la segunda mitad de la década de los 90, para luego recuperarse a un modesto ritmo. Una tendencia similar se observa en el PIB per cápita, sólo que, contrario a lo ocurrido con el departamento, el PIB nacional se contrajo, mostrando el deterioro del ingreso de los colombianos, pese al relativo dinamismo de la economía agregada en los últimos años. El año 2001 fue el peor en cuanto al ingreso por habitante en lo transcurrido de esta década. 
AS DISPARIDADES

INTERPROVINCIALES EN BOYACÁ

Cuadro No. 2

Dinámica del PIB real (tasa de crecimiento \%)

\begin{tabular}{|c|c|c|}
\hline PERIODO & BOYACÁ & COLOMBIA \\
\hline $1990-1995$ & 2,50 & 3,80 \\
$1996-2000$ & $-0,22$ & 0,96 \\
$2001-2005$ & 2,18 & 3.37 \\
\hline
\end{tabular}

Fuente: Dane, cálculos del autor.

Cuadro No. 3

Dinámica del PIB per cápita real (tasa de crecimiento \%)

\begin{tabular}{|c|c|c|}
\hline PERIODO & BOYACÁ & COLOMBIA \\
\hline $1990-1995$ & 2,04 & 2,12 \\
$1996-2000$ & $-1,00$ & $-0,92$ \\
$2001-2005$ & 1,48 & 1,65 \\
\hline
\end{tabular}

Fuente: Dane, cálculos del autor.

Como resultado del mayor ritmo de crecimiento del PIB y de la regresión demográfica, el PIB per cápita experimentó durante la década de los 90 un repunte, lo que se revirtió parcialmente, con la recesión de finales de la década, recuperándose en lo transcurrido del presente decenio, lo que se tradujo en un incremento del coeficiente PIB per cápita departamental/PIB per cápita nacional, siendo el máximo nivel el registrado por Boyacá el alcanzado en 1993, cuando el ingreso per cápita fue de \$ 1.533.166 (88,62\%). Sin embargo, en términos reales el mencionado coeficiente disminuyó, al descender de 80,78\% en 1990 a 78,45\% en 2005.

Cuadro No. 4

Evolución del PIB per cápita real (en \$ constantes de 1994)

\begin{tabular}{|c|c|c|c|}
\hline AÑO & PIBP.C.NACIONAL(\$) & PIBP.C.BOYACÁ(\$) & $\begin{array}{c}\text { COEFICIENTE PIB P.C. DE } \\
\text { BOYACÁ/PIBP.C. } \\
\text { NACIONAL(\%) }\end{array}$ \\
\hline 1990 & 1.626 .380 & 1.313 .816 & 80,78 \\
1991 & 1.631 .521 & 1.324 .171 & 79,93 \\
1992 & 1.668 .878 & 1.345 .391 & 80,61 \\
1993 & 1.729 .910 & 1.533 .166 & 88,62 \\
1994 & 1.784 .264 & 1.455 .183 & 81,55 \\
1995 & 1.843 .363 & 1.469 .313 & 79,70 \\
\hline
\end{tabular}




\begin{tabular}{|c|c|c|c|}
\hline ANO & PIBP.C.NACIONAL(\$) & PIBP.C.BOYACÁ(\$) & $\begin{array}{c}\text { COEFICIENTE PIB P.C. DE } \\
\text { BOYACÁ/PIBP.C. } \\
\text { NACIONAL (\%) }\end{array}$ \\
\hline 1996 & 1.845 .155 & 1.409 .951 & 76,41 \\
1997 & 1.871 .851 & 1.436 .025 & 76,71 \\
1998 & 1.847 .348 & 1.360 .477 & 73,64 \\
1999 & 1.737 .252 & 1.354 .893 & 77,99 \\
2000 & 1.757 .122 & 1.394 .054 & 79,33 \\
2001 & 1.751 .959 & 1.408 .615 & 80,40 \\
2002 & 1.754 .734 & 1.363 .934 & 77,72 \\
2003 & 1.791 .792 & 1.466 .813 & 81,86 \\
2004 & 1.848 .250 & 1.443 .580 & 78,11 \\
2005 & 1.905 .507 & 1.494 .908 & 78,45 \\
\hline
\end{tabular}

Fuente: Dane, Cuentas Regionales.

Al examinar la composición sectorial del PIB real de Colombia es visible el descenso del sector agropecuario. El sector primario se contrajo de 20,04 a $18,13 \%$ durante el lapso 1990-2005, siendo la industria manufacturera la fuente de esta declinación. Simultáneamente, la contribución del sector secundario se redujo de 23,90 a 20,33\%, siendo la industria manufacturera la responsable de esta caída.
Contrario a lo que aconteció con las actividades productoras de bienes transables, el sector terciario ha acentuado su predominio, pese a la pérdida de dinamismo de gran parte de los sectores -exceptuando la intermediación financiera y la Administración Pública-, elevándose su peso relativo de 50,06 a 54,61\%. Los estimativos anteriores, a grandes rasgos, refrendan las tendencias, de largo plazo, las cuales revelan la reestructuración de la economía departamental, a favor del sector terciario.

Cuadro No. 5

Estructura sectorial real del PIB (\%)

\begin{tabular}{|l|c|c|c|c|}
\hline \multirow{2}{*}{ SECTOR } & \multicolumn{2}{|c|}{ COLOMBIA } & \multicolumn{2}{c|}{ BOYACÁ } \\
\cline { 2 - 5 } & 1990 & 2005 & 1990 & 2005 \\
\hline Primario & 20,04 & 18,13 & 33,57 & 24,14 \\
Secundario & 23,90 & 20,33 & 16,77 & 18,33 \\
Terciario & 50,06 & 54,61 & 46,58 & 52,84 \\
Subtotal VA & 94,0 & 93,07 & 96,92 & 95,31 \\
Impuestos & 6,0 & 6,93 & 3,08 & 4,69 \\
TOTAL & 100,0 & 100,0 & 100,0 & 100,0 \\
\hline
\end{tabular}

Fuente: Dane, cálculos del autor. 
En contraste con lo observado a escala nacional, en la estructura sectorial de Boyacá, el declive del sector primario se ha originado más en la minería que en la agricultura, descendiendo de 33,57 a 24,14\% entre 1990 y 2005. Lo anterior se correlaciona con la pérdida del predominio de la población rural $(47,76 \%$, según el censo de población de 2005) y replantea la vocación económica del departamento, la cual se ha trasladado hacia el desigual, en cuanto a tamaño y productividad, sector de servicios.

A diferencia de lo que sucede a nivel del país, la industria boyacense se ha reactivado, induciendo una mayor inserción del sector secundario, el cual representa $18,33 \%$ de la economía departamental, luego de absorber el 16,77\%.

El sector terciario se ha consolidado como el sector ancla de la economía boyacense, aumentando de $46,58 \%$ en 1990 a 52,84\% en 2005. Los subsectores más dinámicos son la intermediación financiera y la Administración pública. Tanto en el estudio del Cega (2004) como en las cifras del Dane, es notorio el repunte logrado por el gobierno o la administración pública, reflejando la importancia de las transacciones que realizan los diferentes niveles de las entidades territoriales.

Los subsectores que mantienen una importancia relativa creciente en la provisión de bienes y servicios en el contexto nacional, son la intermediación financiera, la industria y la administración pública, aportando, en 2005 , el 1,70 , el 2,15 y el $3,40 \%$, respectivamente, del agregado nacional del sector correspondiente. Los demás subsectores han tenido un desempeño declinante, lo que, en últimas, se traduce en la caída de la participación del PIB departamental, aumentando el rezago competitivo, su menor inserción en la economía nacional.

\section{La persistencia de las disparidades interregionales}

La economía colombiana revela un patrón de localización desigual (Moncayo - Garza, 2005), el cual tiende a perpetuarse, aumentando la brecha interregional. Los estudios sobre divergencia, polarización o convergencia (Cárdenas, Bonet y Meisel, entre otros) así lo corroboran. La contribución de Bogotá, Antioquia, Valle, Cundinamarca, Santander y Atlántico, mantuvo, y acentuó su prevalencia en el PIB, acaparando, según las cifras del Dane, el 69,14\% del PIB en el 2005, sobrepasando el nivel registrado en 1990 (65,73\%).

Las cuentas departamentales del Dane desvirtúan un reescalafonamiento de la economía boyacense, pues su posición relativa se mantiene estacionaria: es la octava economía del país desde 1990. Los departamentos que le anteceden son Bogotá, Antioquia, Valle, Cundinamarca, Santander, Atlántico y Bolivar.

La estructura productiva de los departamentos tiene unos perfiles definidos. 
Boyacá tiene una propensión hacia las actividades agromineras, a pesar del creciente desplazamiento del sector primario por el sector terciario en la última década.

Sobre la convergencia regional, medida a través de la dispersión del producto o ingreso per cápita (utilizando el PDB o VAB per cápita, en la medición del Cega), no hay observaciones concluyentes. El estudio del Cega señala que hubo convergencia hasta finales de la década de los 80, para evidenciarse la divergencia en años recientes.

Los estudios efectuados sobre convergencia-divergencia se remontan a comienzos de la década de los 90 y como lo sintetizan Barón y Meisel “ la gran mayoría de los trabajos sobre este tema utilizan principalmente las predicciones del modelo de crecimiento neoclásico que postula que las disparidades espaciales de ingresos per cápita tienden a reducirse con el paso del tiempo y, por lo tanto, la tasa de crecimiento del PIB per cápita departamental estaría inversamente relacionada con el nivel inicial de ingreso. Esta relación entre la renta inicial y su tasa de crecimiento es lo que se conoce como la hipótesis de convergencia. En el caso de regiones dentro de un país, el modelo neoclásico de crecimiento supone la movilidad perfecta de factores, competencia perfecta y funciones de producción regionales idénticas, en la que el producto total depende de la cantidad de factores productivos y del progreso tecnológico, que se determina de manera exógena" (2003: 21-22)

Al cotejarse diversas medidas de disparidad regional ${ }^{9}$, la conclusión es coincidente: esta ha aumentado en las dos últimas décadas.

La hipótesis subyacente en el estudio del Cega es que actualmente existe una distribución más igualitaria del ingreso medio entre los departamentos, resultante de los mayores recursos transferidos por el Gobierno Nacional a los mismos. En efecto, el director del Cega, profesor Luis Lorente, lo resume así: "este es uno de los resultados más interesantes del trabajo: comprobar que la política de descentralización y de transferencias ha sido efectiva y ha contribuido a mejorar la distribución del ingreso promedio entre departamentos" (Cega, 2006: 13-14), recapitulando: "el análisis preliminar de los resultados indica que las transferencias del Gobierno Central a los regionales ha tenido el efecto redistributivo deseado" (2003: 15).

Las anteriores apreciaciones van en contravía de las conclusiones de Barón y Meisel (2003), quienes no encontraron una estrecha asociación entre transferencias de la Nación y reducción de las asimetrías interdepartamentales,

\footnotetext{
9 Se conocen medidas como la razón Máximo-Mínimo, el Índice de Theil, la función de densidad de Kernel, la Convergencia Sigma y Convergencia Beta.
} 
concluyendo : "en este trabajo hemos mostrado que la enorme descentralización fiscal que Colombia adelantó a partir de 1991 no ha contribuido a la reducción de las disparidades regionales”, agregando: "es más, entre 1991 y el 2000 el coeficiente de variación del logaritmo del PIB per cápita, una de las medidas más utilizadas para medir esas disparidades, muestra una tendencia al incremento. Esta es una situación bastante dramática ya que a comienzos de la década de 1990, Colombia era ya un país con profundos desequilibrios en los niveles de desarrollo de sus regiones" (2003: 60). En otros términos, "las disparidades regionales en vez de irse reduciendo han tendido a aumentar durante la última década, es decir, en el periodo en el cual se aceleró la descentralización. Bajo los dos tipos de convergencia la conclusión es la misma: las disparidades tendieron a aumentar en la década del noventa o por lo menos no disminuyeron” (2003: 29).

La anterior conclusión coincide con la formulada por Bonet, quien señala: "Utilizando un conjunto de datos de panel departamental, encontramos una fuerte evidencia a favor de que el proceso de descentralización fiscal aumentó las disparidades regionales en los ingresos durante el periodo analizado", subrayando: "Este comportamiento parece explicarse por un conjunto de factores: la asignación de una proporción importante de los nuevos recursos al gasto corriente (p. Ej. sueldos y salarios) en vez de asignación a capital e infraestructura. La falta de un componente redistributivo en las transferencias nacionales, la ausencia de incentivos adecuados para los niveles subnacionales por parte del nivel nacional con el fin de promover un uso eficiente de ellas, y la carencia de capacidad institucional en los gobiernos subnacionales” (2004: 19).

Una investigación reciente de Bonet y Meisel encontró que "las políticas que se esperarían tuvieran un impacto sobre el desarrollo regional como la descentralización, no parecen tener un impacto positivo sobre las tendencias observadas en el largo plazo. Por el contrario, durante el periodo de su profundización, la concentración del ingreso del gobierno, sociedades no financieras y sociedades financieras en Bogotá se ha incrementado”, añadiendo: "estos hallazgos obligan a pensar en la necesidad de establecer una política de Estado orientada a reducir las enormes diferencias en los ingresos per cápita de sus entes territoriales” (2006: 30).

De otra parte, Barón encontró “que las disparidades no se han reducido durante los últimos 21 años (1980-2001). En efecto, las disparidades parecen estar aumentando” (2004:33). Más adelante, este autor reafirma su apreciación, anotando: "Colombia tiene unas disparidades económicas regionales persistentes. Estas disparidades no disminuyeron en el curso de las dos últimas décadas. Más aún, hay evidencias indicando que estas disparidades están de hecho aumentando” (2004: 37). 


\section{La estructura y tendencias demográficas de las provincias boyacenses}

\subsection{Las provincias boyacenses}

Boyacá está conformada por 13 provincias: Centro, Gutiérrez, La Libertad, Lengupá, Márquez, Neira, Norte, Occidente, Oriente, Ricaurte, Sugamuxi, Tundama y Valderrama.

\section{Cuadro No. 6}

Las provincias de Boyacá

\begin{tabular}{|c|c|}
\hline PROVINCIAS & MUNICIPIOS INTEGRANTES \\
\hline Centro & $\begin{array}{l}\text { Tunja, Cómbita, Cucaita, Chíquiza, Chivatá, Motavita, Oicatá, } \\
\text { Samacá, Siachoque, Sora, Soracá, Sotaquirá, Toca, Tuta, } \\
\text { Ventaquemada. }\end{array}$ \\
\hline Gutiérrez & $\begin{array}{l}\text { Cubará, Chiscas, El Cocuy, El Espino, Guacamayas, Güicán, } \\
\text { Panqueba. }\end{array}$ \\
\hline La Libertad & Labranzagrande, Pajarito, Paya, Pisba. \\
\hline Lengupá & $\begin{array}{l}\text { Berbeo, Campohermoso, Miraflores, Páez, San Eduardo, } \\
\text { Zetaquira. }\end{array}$ \\
\hline Márquez & $\begin{array}{l}\text { Boyacá, Ciénega, Jenesano, Nuevo Colón, Ramiriquí, Rondón, } \\
\text { Tibaná, Turmequé, Umbita, Viracachá. }\end{array}$ \\
\hline Neira & $\begin{array}{l}\text { Chinavita, Garagoa, Macanal, Pachavita, san Luis de Gaceno, } \\
\text { Santa María. }\end{array}$ \\
\hline Norte & $\begin{array}{l}\text { Boavita, Covarachía, La Uvita, San Mateo, Sativanorte, } \\
\text { Sativasur, Soatá, Susacón, Tipacoque. }\end{array}$ \\
\hline Occidente & $\begin{array}{l}\text { Briceño, Buenavista, Caldas, Coper, Chiquinquirá, La Victo- } \\
\text { ria, Maripí, Muzo, Otanche, Pauna, Puerto Boyacá, Quípama, } \\
\text { Saboyá, San Miguel de Sema, San Pablo, Tununguá. }\end{array}$ \\
\hline Oriente & $\begin{array}{l}\text { Almeida, Chivor, Guateque, Guayatá, La Capilla, Somondoco, } \\
\text { Sutatenza, Tenza. }\end{array}$ \\
\hline Ricaurte & $\begin{array}{l}\text { Arcabuco, Chitaraque, Gachantivá, Moniquirá, Ráquira, Sáchica, } \\
\text { San José de Pare, Santa Sofía, Santana, Sutamarchan, Tinjacá, } \\
\text { Togui, Villa de Leyva. }\end{array}$ \\
\hline Sugamuxi & $\begin{array}{l}\text { Aquitania, Cuitiva, Firavitoba, Gámeza, Iza, Mongua, Monguí, } \\
\text { Nobsa, Pesca, Tibasosa, Tópaga, Tota, Sogamoso. }\end{array}$ \\
\hline Tundama & $\begin{array}{l}\text { Belén, Busbanzá, Cerinza, Corrales, Duitama, Floresta, Paipa, } \\
\text { Santa Rosa de Viterbo, Tutazá. }\end{array}$ \\
\hline Valderrama & Beteitiva, Chita, Jericó, Paz de Río, Socotá, Tasco. \\
\hline
\end{tabular}


La estructura productiva del departamento no se ha diversificado suficientemente. Tal como se señaló al comienzo de este ensayo, el sector terciario ha desplazado a los sectores de bienes transables como son la agricultura y la industria. El comercio se ha convertido en la actividad jalonadora de la economía provincial, siendo los establecimientos de pequeña escala los responsables del dinamismo o retraimiento de la economía local y provincial.

Cuadro No. 7

Perfiles productivos de las provincias

\begin{tabular}{|l|c|c|c|c|c|}
\hline PROVINCIA & INDUSTRIA & COMERCIO & $\begin{array}{c}\text { SERVICIOS } \\
\text { Y OTRAS }\end{array}$ & $\begin{array}{c}\text { ACTIVIDAD } \\
\text { DOMINANTE }\end{array}$ & $\begin{array}{c}\text { ESTABLECI } \\
\text { MIENTOS } \\
\text { DE MENOS } \\
\text { DE } 10 \\
\text { PERSONAS }\end{array}$ \\
\hline Centro & & & & & \\
Gutiérrez & 10,1 & 62,8 & 27,1 & Comercio & 98,5 \\
La Libertad & 13,1 & 57,4 & 29,5 & Comercio & 98,4 \\
Lengupá & 12,4 & 46,6 & 44,7 & Comercio & 96,9 \\
Márquez & 14,4 & 57,6 & 30,0 & Comercio & 99,3 \\
Neira & 13,8 & 59,7 & 25,9 & Comercio & 99,1 \\
Norte & 13,6 & 55,0 & 31,2 & Comercio & 98,7 \\
Occidente & 6,8 & 56,0 & 30,4 & Comercio & 97,8 \\
Oriente & 20,0 & 56,8 & 36,4 & Comercio & 97,9 \\
Ricaurte & 22,2 & 44,3 & 35,7 & Comercio & 98,1 \\
Sugamuxi & 12,7 & 46,5 & 31,3 & Comercio & 91,2 \\
Tundama & 13,8 & 59,7 & 27,6 & Comercio & 98,3 \\
Valderrama & 7,5 & 63,3 & 23,0 & Comercio & 96,9 \\
Total & & 65,1 & 27,4 & Comercio & 98,5 \\
\hline
\end{tabular}

Fuente: Dane, Censo de Población, 2005.

\subsection{Composición y mutaciones poblacionales}

Durante el periodo intercensal de 19932005 se han producido cambios demográficos sustanciales. Según el último censo de población el $66,5 \%$ de la población expulsada de Boyacá se residenció en Bogotá, siguiéndole Cundinamarca $(13,5 \%)$ y Casanare (4,6\%). A su vez, de la población que migró hacia Casanare -departamento que tiene vínculos ancestrales con Boyacá- 24,4\% provino de Boyacá. Si a ello se añade que el 10,3\% que se asentó en Bogotá durante los últimos cinco años procedía de Boyacá.

No obstante que la población de Boyacá se elevó en 37.155 habitantes, el balance interprovincial es negativo.De tiempo atrás, es palpable cómo algunas de las pro- 
vincias que lo integran se han convertido en expulsoras. Ese es el caso de provincias como Gutiérrez, La Libertad, Lengupá, Márquez, Neira, Norte, Oriente y Valderrama. El éxodo registrado en estas ocho provincias alcanzó las 66.620 personas. De otro lado, las demás provincias experimentaron un crecimiento pobla-cional, que compensó las tendencias hacia el vaciamiento de algunas poblaciones que evidenciaron un notorio declive. La hipótesis más plausible es que los emigrantes se desplazaron a otras provincias o se asentaron en departamentos vecinos como Santander o Casanare, o engrosaron la población de Bogotá.

Las ciudades capitales de provincia tendieron a concentrar una proporción dominante de la población provincial en el último censo, así: Tunja (57,9\%), Cubará (21,1\%), Labranzagrande (45,6\%), Miraflores (37,2\%), Úmbita (15,0\%), Garagoa (42,5\%), Soatá (23,2\%), Chiquinquirá (27,8\%), Guateque (27,9\%), Moniquirá (23,3\%), Sogamoso (56,9\%), Duitama (62,3\%) y Chita (22,5\%). Simultáneamente con la aglomeración de población en las principales cabeceras municipales, se observa en los municipios expulsores una caída de la densidad poblacional, en tanto que en los receptores una disminución de la misma.

Entre los 123 municipios del departamento, Tunja es la ciudad más densificada: 1.291,7 habitantes por kilómetro cuadrado, superando, ampliamente, el promedio departamental: 52,2 personas. Simultáneamente, la provincia que mayor densificación poblacional exhibe es la del Centro (144,1 personas), seguido de Tundama (133,3 personas).

La dinámica poblacional ${ }^{10}$ de las provincias boyacenses ha puesto de manifiesto cómo el vaciamiento registrado en el periodo intercensal condujo a una reducción del peso relativo de gran parte de las provincias (ocho de las trece), mientras que se acentuó la primacía de cuatro provincias determinantes en el desarrollo departamental: Centro que ganó cuatro puntos, Occidente que marcó una diferencia de 1,8 puntos, Tundama que se elevó en 0,4 puntos y Sugamuxi en 0,1. Estas cuatro provincias, en donde se encuentra enclavado el corredor industrial y donde se localizan las principales dependencias de la administración pública, acaparan el $68,3 \%$ de la población de Boyacá.

\footnotetext{
10 Recientemente la Gobernación de Boyacá promovió la realización de monografías provinciales acerca del estudio de la dimensión poblacional a partir de la metodología para el análisis de tensiones, interacciones y balances en dinámicas y desarrollos poblacionales, ambientales, sociales y económicos elaborada por el Ministerio de Ambiente, Vivienda y Desarrollo Territorial. Estos estudios de Balances Interacciones y Tensiones (BIT) en las dimensiones poblacional, ambiental, social y económica (PASE), que se remontan al censo de 1973 y abarca un conjunto amplio de variables demográficas, fueron desarrollados por estudiantes tesistas de la Escuela de Economía, constatando que, en la mayor parte de las provincias, la expulsión de la población fue su denominador común. Véase Metodología para el análisis de tensiones, interacciones y balances en dinámicas y desarrollos poblacionales, ambientales, sociales y económicos, Ministerio de Ambiente, Vivienda y Desarrollo Territorial, Serie Población, Ordenamiento y Territorio No. 3, 2004, Bogotá D.C.
} 
El balance demográfico interprovincial negativo se le ha atribuido -como lo evidenciaron recientes monografías elaboradas por estudiantes tesistas de la Escuela de Economía de la UPTC-, predominantemente, por el aumento del crecimiento migratorio que no es compensado por el crecimiento vegetativo de la población. La hipótesis más plausible es que las zonas rurales han reducido su población que -por la carencia o estrechez de oportunidadesse ha volcado a las cabeceras municipales.
Lo más relevante de lo acontecido en la última década es la expansión demográfica de Puerto Boyacá, polo atractor de los migrantes del Magdalena Medio por su condición de puerto petrolero, aumentando su población en 21.360 personas, equivalente a un incremento de $74,8 \%$, por encima del observado para todo el departamento: 3,2\%. Puerto Boyacá se ha desenvuelto como un enclave mineroextractivo, siendo el municipio más extenso del departamento (1.472 kilómetros), registrando, como se anotó atrás, un aluvional crecimiento demográfico.

Cuadro No. 8

Perfiles demográficos de las provincias

\begin{tabular}{|l|c|c|c|c|c|c|c|}
\hline Provincia & $\begin{array}{c}\text { Población } \\
1993\end{array}$ & $\%$ & $\begin{array}{c}\text { Población } \\
2005^{11}\end{array}$ & $\%$ & $\begin{array}{c}\text { Direncial } \\
\text { Poblacional }\end{array}$ & \multicolumn{2}{|c|}{$\begin{array}{c}\text { Densidad } \\
\text { Poblacional } \\
\text { (habitantes/km2) }\end{array}$} \\
\hline Centro & 207.473 & 17,7 & 262.978 & 21,7 & 55.505 & 113,7 & 144,1 \\
Gutiérrez & 36.422 & 3,1 & 30.677 & 2,5 & -5.745 & 11,7 & 9,9 \\
La Libertad & 14.129 & 1,2 & 11.467 & 1,0 & -2.662 & 10,0 & 8,2 \\
Lengupá & 26.700 & 2,3 & 25.391 & 2,1 & -1.309 & 20,2 & 19,2 \\
Márquez & 69.854 & 6,0 & 66.005 & 5,4 & -3.849 & 76,7 & 72,4 \\
Neira & 38.772 & 3,3 & 30.081 & 3,1 & -691 & 16,2 & 16,0 \\
Norte & 64.876 & 5,5 & 37.578 & 3,1 & -27.293 & 59,3 & 34,4 \\
Occidente & 170.300 & 14,5 & 197.512 & 16,3 & 27.212 & 38,0 & 44,1 \\
Oriente & 47.499 & 4,0 & 35.491 & 2,9 & -12.008 & 76,5 & 57,1 \\
Ricaurte & 87.537 & 7,4 & 91.569 & 7,6 & 4.032 & 56,4 & 59,0 \\
Sugamuxi & 194.317 & 16,5 & 201.569 & 16,6 & 7.252 & 79,0 & 81,9 \\
Tundama & 156.767 & 13,3 & 166.546 & 13,7 & 6.779 & 125,5 & 133,3 \\
Valderrama & 59.385 & 5,2 & 46.322 & 4,0 & -13.063 & 31,3 & 24,4 \\
Total & 1.174 .031 & 1.211 .186 & 371.555 & 100,0 & 100,0 & 50,6 & 52,2 \\
\hline
\end{tabular}

Fuente: Dane, Censos de población de 1993 y 2005. Cálculos del autor.

\footnotetext{
11 Según el Dane existen diferencias marcadas entre la población censada compensada y la población conciliada en el 2005, incluyendo esta última los faltantes de población no censada o porcentaje de omisión o no cobertura censal. Mientras la población censada para Colombia fue de 42.090.502 habitantes, la población conciliada fue de 42.888 .592 personas. En el caso de Boyacá estas cifras correspondieron a 1.211.186 y 1.255.311 personas. Al revisarse los estimativos de los censos de 1993 y 2005 se encontrará que la población se redujo; la población se comprimió de 1.315 .579 en 1993 a 1.255 .311
} 


\section{La recurrencia de la inequi- dad social}

Boyacá es uno de los departamentos donde, pese a la relativa reactivación económica de los últimos años, persiste una tendencia regresiva en la equidad social, superando los principales indicadores los niveles identificados a escala nacional. De la información analizada se puede determinar que existe una correspondencia estrecha entre las provincias de mayor rezago económico y mayor atraso social, siendo a su vez donde los flujos migratorios son más intensos, provocando el fenómeno, atrás reseñado, de vaciamiento poblacional. Las precarias condiciones en que se desenvuelve la población son tales que no es posible retenerla en su terruño.

Uno de los indicadores que evidencia el bienestar colectivo es el Índice de Condiciones de Vida (ICV), correlato del Índice de Necesidades Básicas Insatisfechas (NBI); "el ICV incluye más dimensiones que el NBI, da valoraciones distintas a las diferentes condiciones de vida y permite que vayan cambiando en el tiempo"(DNP,2001: 16). De otro lado, la medición de la Línea de Pobreza (LP) "informa que cierto porcentaje de la población no cuenta con los ingresos necesarios con respecto a un valor dado, Línea de Pobreza, o que sus ingresos no son suficientes para satisfacer los requerimientos nutricionales básicos de una familia” (DNP, 2001: 22).
Entre los tres indicadores mencionados, el ICV refleja mejor la concepción del Nobel de Economía, Amartya Sen, que postula que "el bienestar se fundamenta en las capacidades o potencialidades de que disponen los individuos y en la distribución y acceso a los recursos privados y colectivos que les permite tener una vida digna” (DNP, 2001:16). Asimismo, cabe señalar, con respecto a la LP, que "los indicadores que tienen como fundamento los ingresos no da razón directamente de las capacidades y potencialidades de los individuos, ni sobre el acceso que ellos tienen a los bienes y servicios públicos, ni de las elecciones que realiza el consumidor" (DNP, 2001:22).

El bajo ritmo de crecimiento demográfico observado en gran parte de las provincias de Boyacá ha estado acompañado de una mejoría en el estándar de vida de la población, de su hábitat, del capital humano, de un mayor nivel de escolaridad de los integrantes de los hogares. La provincia que ostenta el ICV más elevado, cercano al promedio nacional, es la de Oriente (70,0 frente a $73,0)$, y por encima del promedio de Boyacá $(62,1)$; en tanto que la que se sitúa en el extremo inferior del escalafón es la de La Libertad. En ambos casos la involución demográfica en el periodo intercensal 1993-2005 fue notoria, así como la reducción de la densidad poblacional subproducto del vaciamiento observado. De otra parte, el mayor nivel de NBI se encuentra en la provin- 
cia de La Libertad $(77,0)$, mientras en la de Sugamuxi se registró el menor $(36,0)$, por debajo del promedio de Boyacá $(39,3)$ y del de Colombia $(52,1)$, en esta provincia aumentó la densificación poblacional.

Boyacá es, después del Chocó, el departamento que más agobia la pobreza y la miseria. La provincia de La Libertad es donde la pobreza tiene mayor incidencia, superando el promedio, tanto de Boyacá como el agregado nacional. La línea de pobreza (LP) osciló entre el 93,9\% de la provincia de La Libertad y $81,8 \%$ de la de Sugamuxi, siendo niveles muy elevados, que sobrepasan el observado para todo el departamento. Similar a lo encontrado con la LP la línea de miseria (LM) o pobreza extrema mostró un patrón homogéneo alcanzando la máxima cota en la provincia Norte $(80,7 \%)$ y la menor en la de Tundama (58,2\%), superando los niveles registrados en Colombia y Boyacá: 17,9 y 41,5\%, respectivamente. Salvo, algunas excepciones, se aprecia una estrecha correspondencia entre la trayectoria de NBI y las LP y LM, no así con el ICV.

En las tres provincias donde gravita el 52\% de la población del departamento (Centro, Sugamuxi y Tundama) se ha dado una sustancial mejoría en las condiciones de vida, distanciándose de provincias como La Libertad, Lengupá y Márquez. La provincia de Occidente, azotada por múltiples violencias, muestra un abultado nivel carencias y pobre- za, a pesar que su ICV es cercano, por ejemplo, al de la provincia Centro y superior al de Sugamuxi. Todas las provincias, sin excepción, se encuentran distantes del promedio de LP y LM, tanto para Boyacá como Colombia.

Las provincias de Lengupá, Occidente y Ricaurte exhibieron el mayor déficit habitacional, particularmente en la zona urbana, mientras que en las zonas rurales, paradójicamente, la provincia Centro concentra el mayor número de destechados $(4,1 \%)$.

La mortalidad en menores de cinco años no revela cambios pronunciados entre las diferentes provincias, bordeando el promedio departamental (1,9\%), excepto en Occidente y Centro.

La escolaridad guarda muchas similitudes, registrando el mayor nivel en la provincia de Tundama (8,3 años), encontrándose el menor en las provincias de Lengupá $(4,9)$ y La Libertad $(5,2)$, siendo un factor que conspira contra la elevación del capital humano, fuente de perpetuación de la pobreza y de la miseria.

Paralelamente a indicadores como NBI e ICV que incorporan las características físicas de la vivienda que habitan los boyacenses y el acceso a los servicios públicos domiciliarios, se observa que la cobertura a tendido a universalizarse, principalmente, en las zonas urbanas, teniendo la menor cobertura la provincia de la Libertad. En las zonas rurales 
existe una brecha considerable, siendo la provincia, anteriormente mencionada la que muestra el menor cubrimiento (26,5\%). La dotación de alcantarillado es aún muy precaria; nuevamente es la provincia de la Libertad la que carece de tan vital servicio. Sólo el 31,2\% de los pobladores urbanos posee este servicio. El mayor nivel se encuentra en la provincia de Gutiérrez (95,5\%).

Las condiciones de deterioro de los indicadores sociales se perpetúan, si no se formulan focalizadas políticas públicas, tanto en el ámbito nacional como regional, que mitiguen la incidencia de la inequidad y la exclusión concomitante, particularmente, en los grupos sociales más vulnerables. La mejoría en la calidad de vida ha sido desigual en las provincias boyacenses, dándose una circularidad perversa entre involución demográfica y erosión social.

A partir de los compromisos adquiridos por el gobierno colombiano en la Cumbre del Milenio en el año 2000, se expidió el Conpes social 091 de 2005 (Metas y estrategias de Colombia para el logro de los Objetivos de Desarrollo del Milenio, ODM-2015), que abarca 8 objetivos, 18 metas y 48 indicadores.
El gobierno de Boyacá en el Consejo de Política Social en diciembre de 2006 emprendió la tarea de elaborar las directrices de la aplicación de los ODM, teniendo como "propósito de identificar y socializar los lineamientos departamentales para alcanzar las Metas del Milenio y erradicar los niveles de pobreza en Boyacá" (Gobernación de Boyacá, 2007: 10). Los objetivos están centrados en la disminución de la pobreza, aumento de la cobertura educativa, la equidad de género, la reducción de la mortalidad infantil, la mejoría en la salud materna, la lucha contra el VIH/ SIDA y las enfermedades endémicas, el saneamiento básico y la sostenibilidad ambiental. En Boyacá el desafío de elevar el bienestar de la población más vulnerable es inaplazable por el deterioro creciente de los indicadores sociales.

Las políticas que se han implantado son cortoplacistas y efectistas, tal como acontece con el llamado Plan Papa, de ración alimenticia para la población escolar, programa que venía adelantando, de tiempo atrás, el Instituto de Bienestar Familiar (ICBF) y, que en la actual Administración departamental adquirió los visos de un programa social "punta de lanza” contra la marginalidad social. 


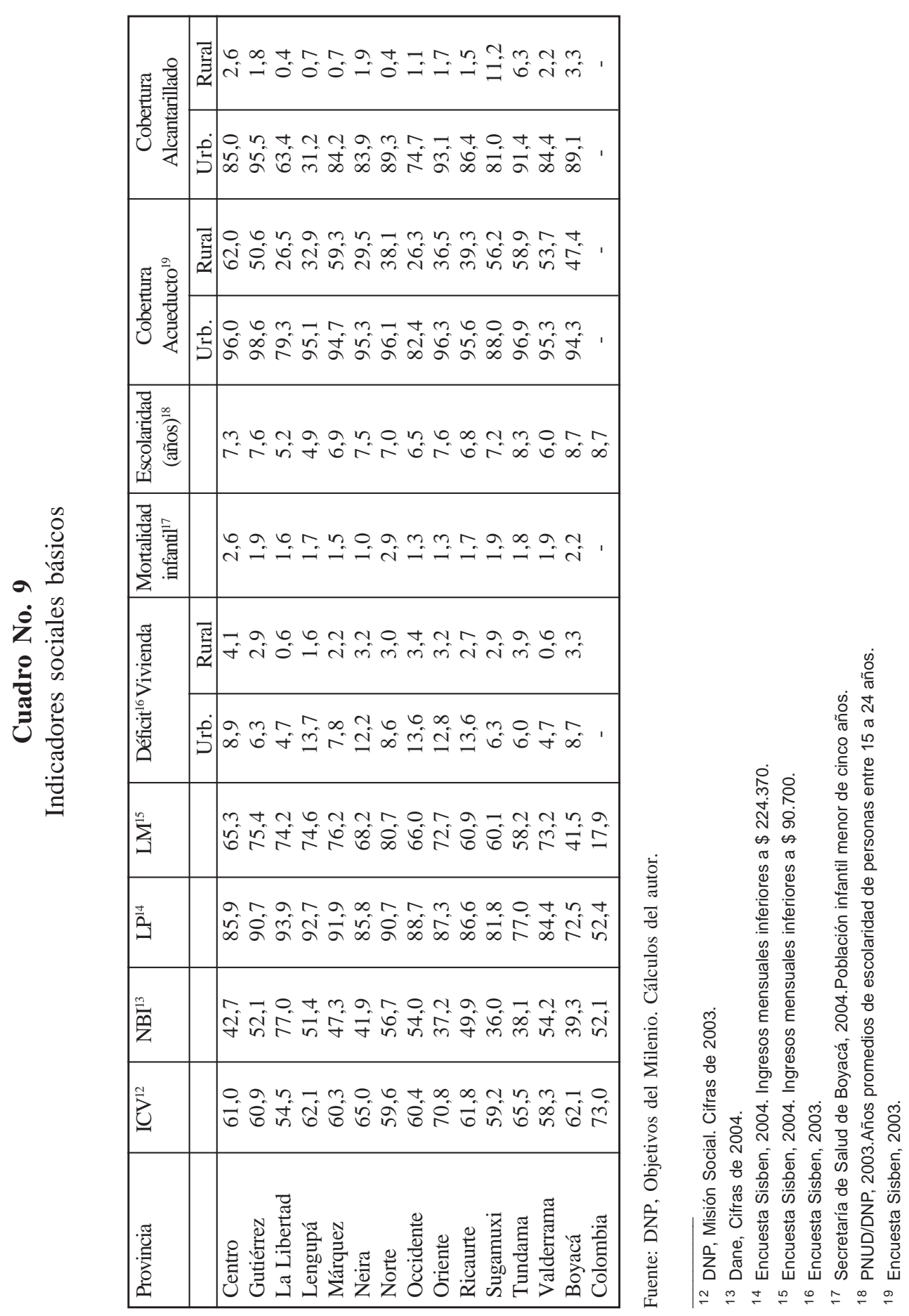




\section{A manera de conclusión}

Tal como se observa en el contexto nacional, en el que las desigualdades interdepartamentales han venido aumentando, evidenciando tendencias divergentes, en el ámbito provincial de Boyacá, se aprecia el rezago de algunas provincias, particularmente, en torno a indicadores sociales, que denotan los avances o retrocesos logrados en la superación de la pobreza y la miseria.

En Boyacá se ha dado una involución demográfica que se refleja en un vaciamiento relativo de la población de algunas provincias que son las que tienen las mayores precariedades y restricciones en su desarrollo.

El deterioro social, acompañado de la inequidad y exclusión, refuerza las tendencias regresivas demográficas, conduciendo a un perverso "círculo vicioso".

Frente a la situación de profundas brechas interprovinciales que se añaden a las existentes en el plano de los desequilibrios interdepartamentales, se han adoptado medidas aisladas de corte asistencialista que atenúa los efectos, pero no contrarresta sus verdaderas causas, afincadas en las oportunidades de empleo y obtención de ingresos que mejoren su acceso a los diferentes bienes y servicios, y, de esa manera, mejoren la calidad de vida de la población.

Pese a que la Administración departamental está empeñada en alcanzar los denominados Objetivos del Milenio (ODM) en el horizonte previsto, la persistencia de las raíces estructurales de la inequidad y exclusión social malogra los modestos avances obtenidos.

\section{Bibliografía}

BARÓN, Juan David y Adolfo Meisel (2003), La descentralización y las disparidades económicas regionales en Colombia en la década de 1990. Documentos de Trabajo sobre Economía Regional, No. 36, julio, Centro de Estudios Económicos Regionales, Banco de la República, Cartagena de Indias.

BARÓN, Juan David, Gerson Pérez y Peter Rowland (2004), Consideraciones para una política económica regional en Colombia. Documentos de Trabajo sobre Economía Regional, No. 52, noviembre, Centro de Estudios Económicos Regionales, Banco de la República, Cartagena de Indias.

BONET, Jaime y Adolfo Meisel (1999), “La convergencia regional en Colombia: una visión de largo plazo, 1926-1995”, en Coyuntura Económica, Vol. 29, No. 1, Fedesarrollo, Bogotá D.C..

BONET, Jaime (2004), Descentralización fiscal y disparidades en el ingreso nacional: la experiencia colombiana. Documentos de Trabajo sobre Economía Regional, No. 49, noviembre, Centro de Estudios Económicos Regionales, Banco de la República, Cartagena de Indias. 
y Adolfo Meisel (2006), Polarización del ingreso per cápita departamental en Colombia, 1875-2000. Documentos de Trabajo sobre Economía Regional, No. 76, julio, Centro de Estudios Económicos Regionales, Banco de la República, Cartagena de Indias.

(2006a), Desequilibrios regionales en la política de descentralización en Colombia. Documentos de Trabajo sobre Economía Regional, No. 77, octubre, Centro de Estudios Económicos Regionales, Banco de la República, Cartagena de Indias.

BOISIER, Sergio (1997), "El vuelo de una cometa. Una metáfora para una teoría del desarrollo territorial”, en Revista EURE, No. 69, Instituto de Estudios Urbanos, Universidad Católica de Chile.

(1999), Desarrollo regional: modelos reales y modelos mentales, en Terra Nostra, No. 4, UPTC, Tunja.

CÁRDENAS, Mauricio y Adriana Pontón (1993), “Convergencia y migraciones interdepartamentales en Colombia: 19501989”, en Coyuntura Económica, Vol. 23, No. 1, Fedesarrollo, Bogotá D.C.

(2005), "Crecimiento económico en Colombia: 1979-2005”, en Coyuntura Económica, Vol. 35, No. 2, Fedesarrollo, Bogotá D.C.

CEGA(2004), Sistema Simplificado de Cuentas Departamentales de Colombia 1975-2000. Volumen 1. Bogotá D. C.

CEGA (2006), Ingreso, consumo y ahorro en los departamentos de Colombia 1975-2000. Volumen 2. Bogotá D. C.

CENTRO DE INVESTIGACIONES PARA
EL DESARROLLO (CID), 2002, Los indicadores sociales, algunos resultados para los municipios de Colombia, Universidad Nacional, Bogotá, D.C..

CUERVO, Luis Mauricio (1999). “El rompecabezas de la intervención económica territorial”, en Territorios, No.2, febrero julio de 1999, Cider-Aciur-Ideade, Universidad de los Andes - Universidad Javeriana, Bogotá D.C.

CUERVO, Luis Mauricio (2003), Pensar el territorio: los conceptos de ciudad global y región en sus orígenes y evolución, Serie Gestión Pública, Instituto Latinoamericano y del Caribe de Planificación Económica y Social (ILPES), No. 40, noviembre, Santiago de Chile.

DEPARTAMENTO NACIONAL DE PLANEACIÓN (DNP), (s.f.), La importancia del ordenamiento territorial en la integración, la competitividad y el desarrollo, DDT, Bogotá, D.C.

DNP (2001), SISD 30, Coyuntura económica e indicadores sociales, Bogotá D.C.

DNP (2006), Bases del Plan Nacional de Desarrollo 2006-2010, Bogotá D. C.

DE MATTOS, Carlos (2000), “Nuevas teorías del crecimiento económico: una lectura desde la perspectiva de los territorios de la periferia”, en Revista Estudios Regionales, No. 58, Universidad de la Rioja, España.

DE ZUBIRÍA, Andrés (1994), Constitución y descentralización territorial, ESAP, Bogotá D.C.

FALS BORDA, Orlando (1996), Región e historia, TM Editores-IEPRI(UN), Bogotá D.C. 
. (1999), “Guía práctica del ordenamiento territorial en Colombia: contribución para la solución de conflictos”, Revista Análisis Político, No. 36, Eneroabril, IEPRI, Universidad Nacional de Colombia, Bogotá D.C.

(2001), Kaziyadu. Registro del reciente despertar territorial en Colombia, Ediciones desde abajo, Bogotá D.C.

GOBERNACIÓN DE BOYACÁ(1997), Perfiles provinciales, Tunja.

GOBERNACIÓN DE BOYACÁ (2007), Hacia un desarrollo de Boyacá incluyente y equitativo, Tunja.

LIRA, Luis (2003), La cuestión regional y local en América Latina, Serie Gestión Pública, Instituto Latinoamericano y del Caribe de Planificación Económica y Social (ILPES), No. 44, noviembre, Santiago de Chile.

MINISTERIO DE AMBIENTE, VIVIENDA Y DESARROLLO TERRITORIAL (2004), Metodología para el análisis de tensiones, interacciones y balances en dinámicas y desarrollos poblacionales, ambientales, socia- les y económicos, Serie Población, Ordenamiento y Desarrollo, Guía Metodológica 3, Bogotá D.C.

MONCAYO, Edgard (2004), Nuevos enfoques del desarrollo territorial: Colombia en una perspectiva latinoamericana, Universidad Nacional- PNUD- CEPAL, Bogotá D. C.

MONCAYO, Edgard- Nestor Garza (2005), "Cambio estructural y transformaciones espaciales en Colombia 1975-2000”, en Economía \& Región, Vol. 2 No. 3, julio, Universidad Tecnológica de Bolivar, Cartagena de Indias.

PORRAS, Oswaldo et al (s.f.), Ordenamiento territorial colombiano y el marco normativo, Departamento Nacional de Planeación, DDT, Bogotá D.C.

RODRÍGUEZ, Edilberto (2007): “Los contornos de la economía departamental en las últimas dos décadas”, en Modelos de desarrollo y economía regional, Edilberto Rodríguez AraújoLuis Eudoro Vallejo Zamudio, Compiladores (2007), Facultad de Ciencias Económicas y Administrativas, Universidad Pedagógica y Tecnológica de Colombia, Tunja. 


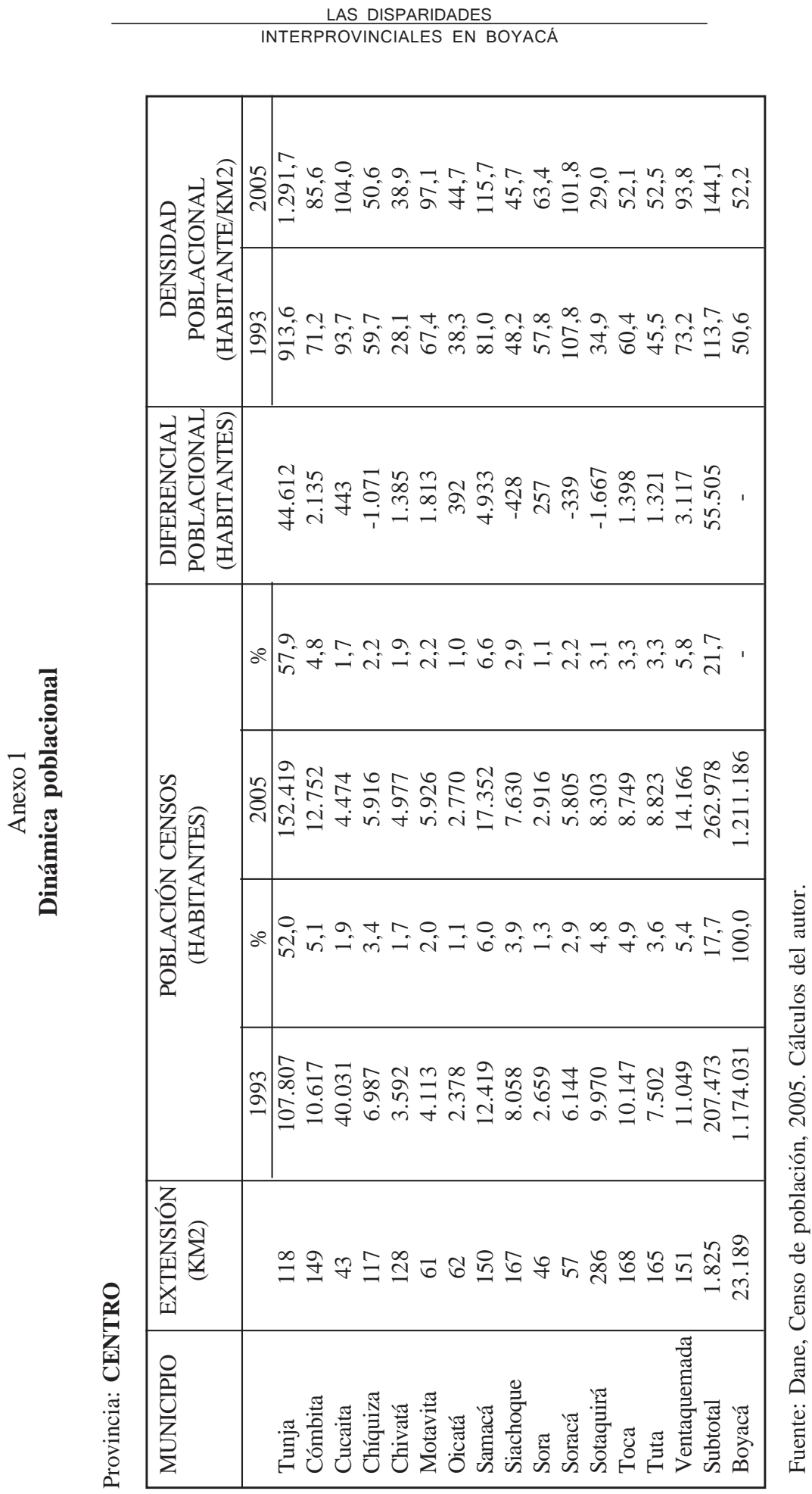




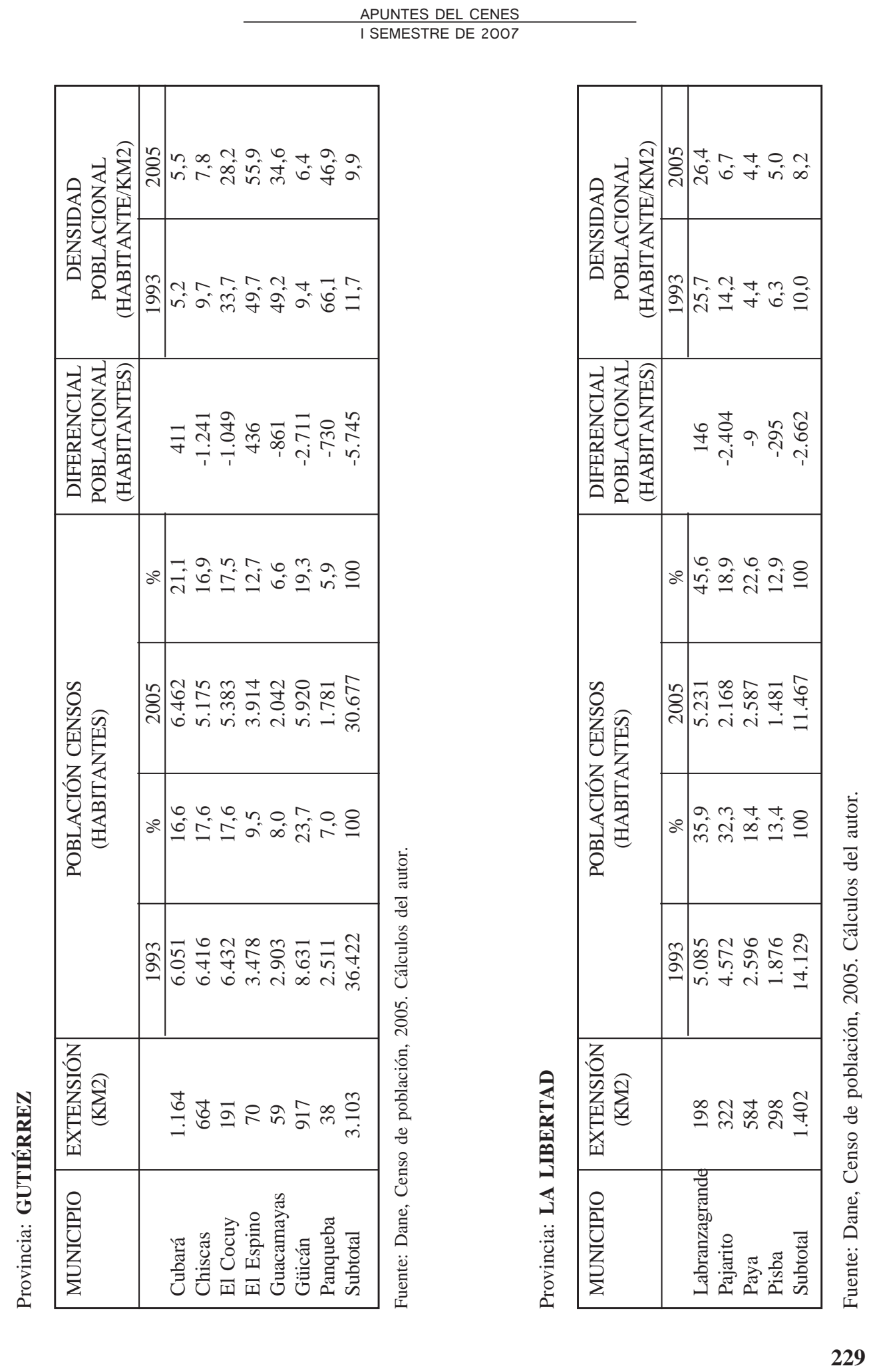



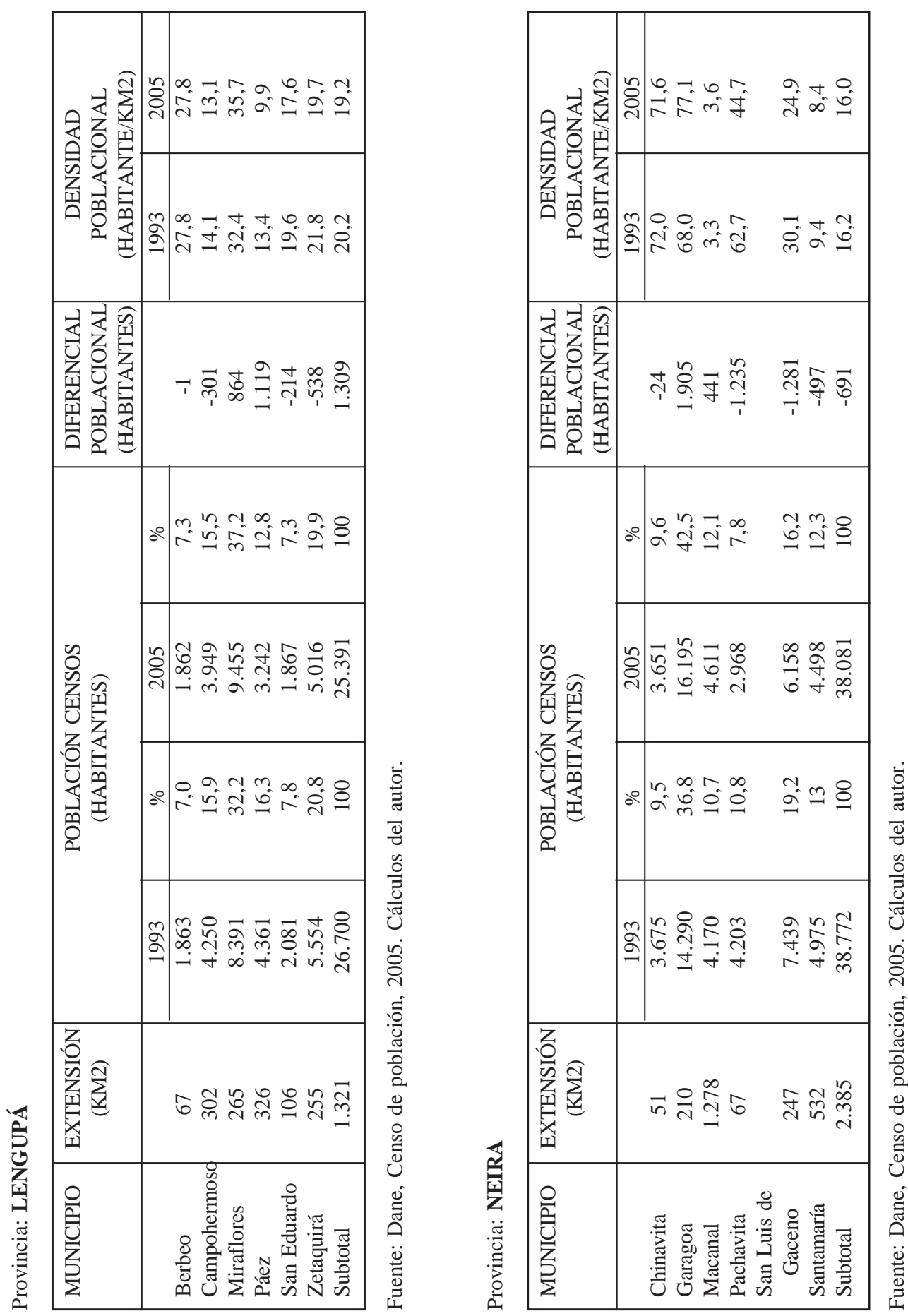


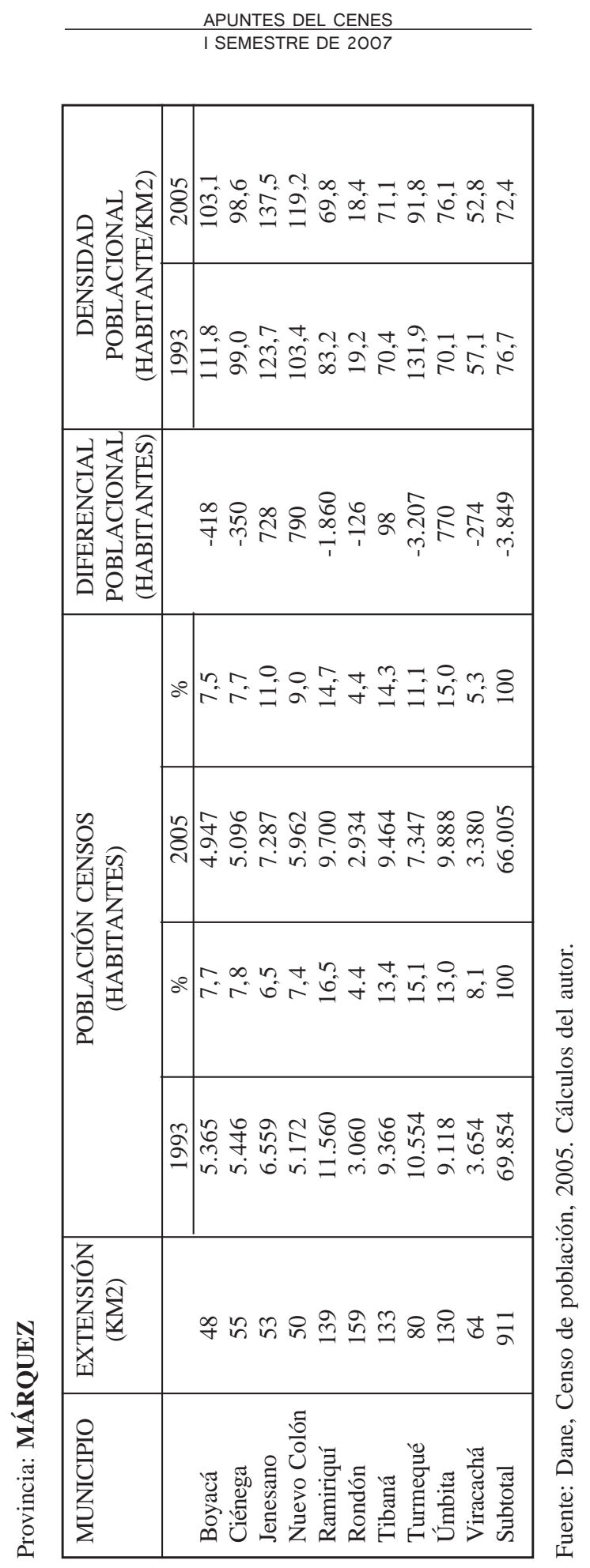




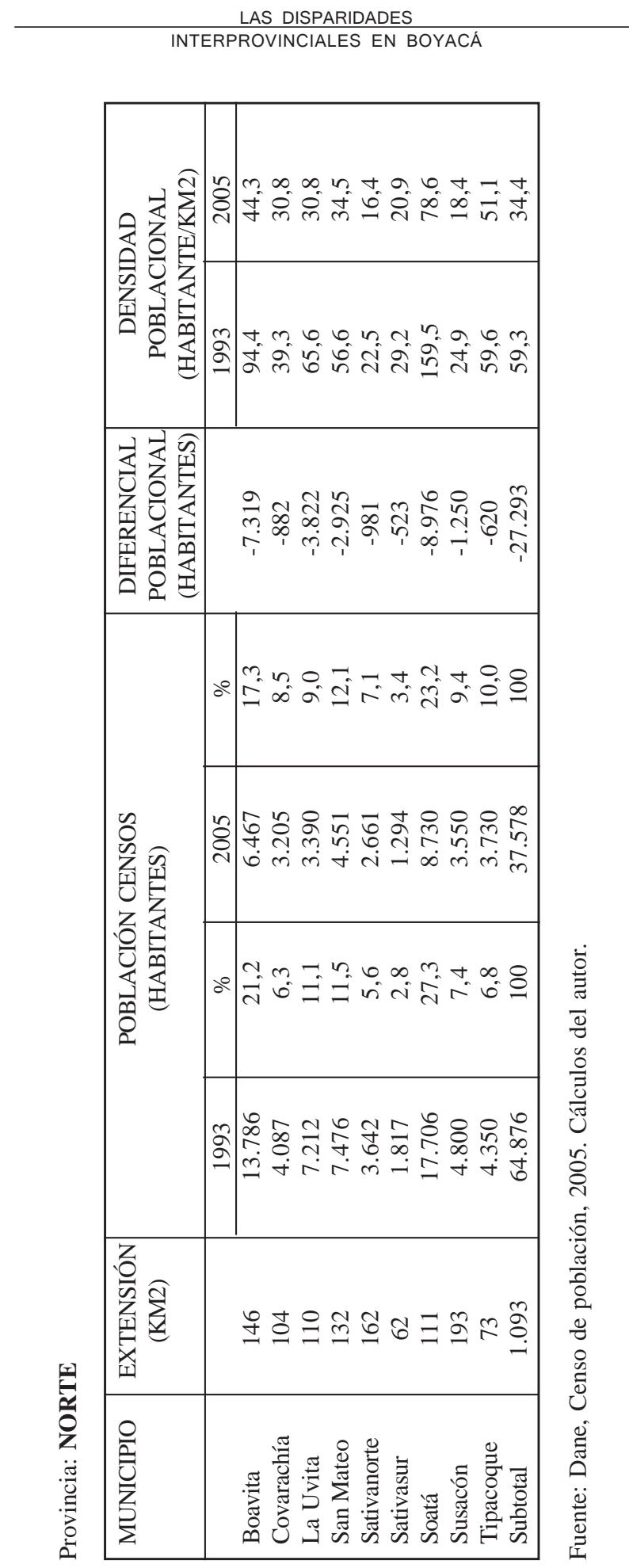




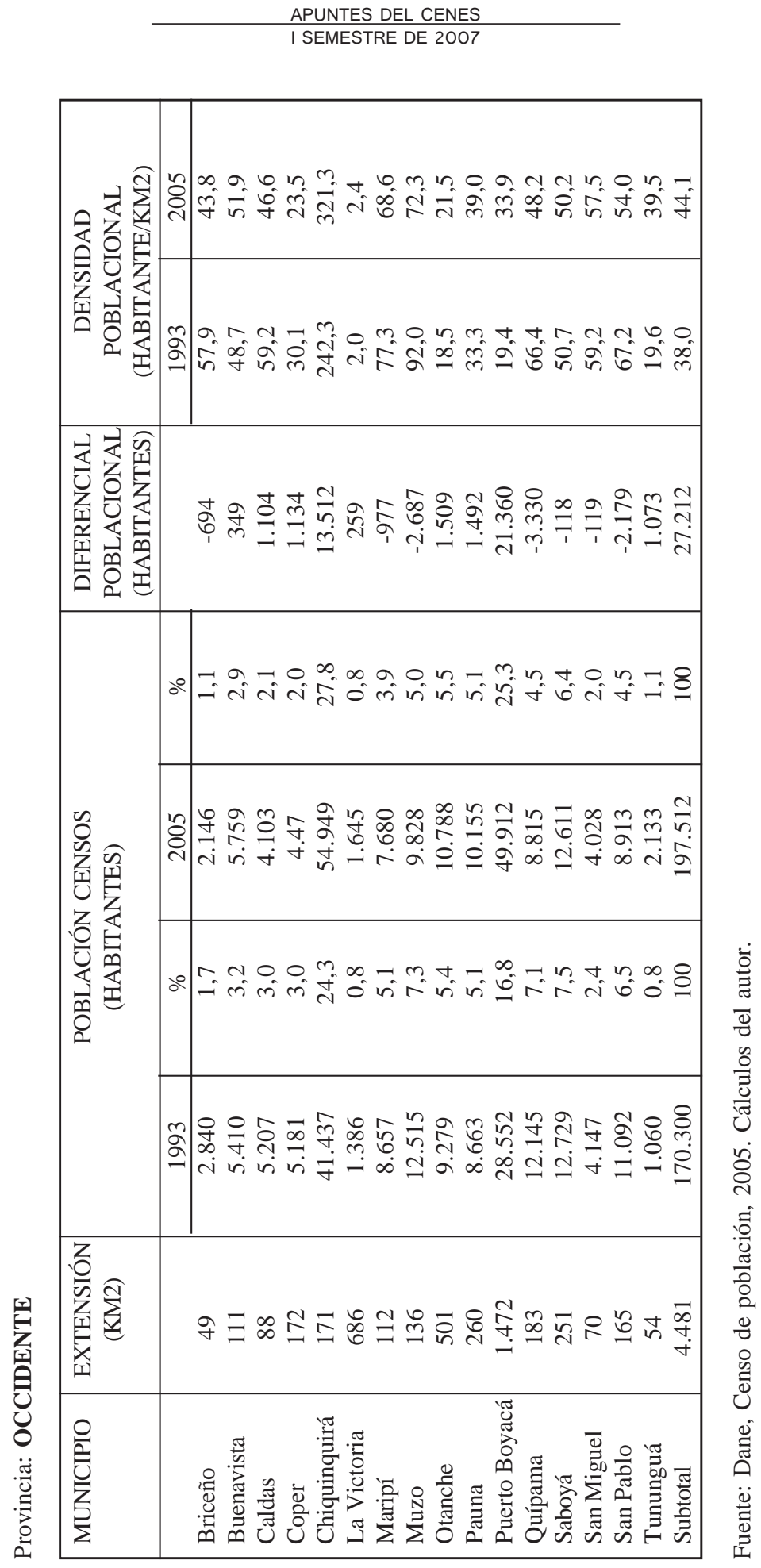




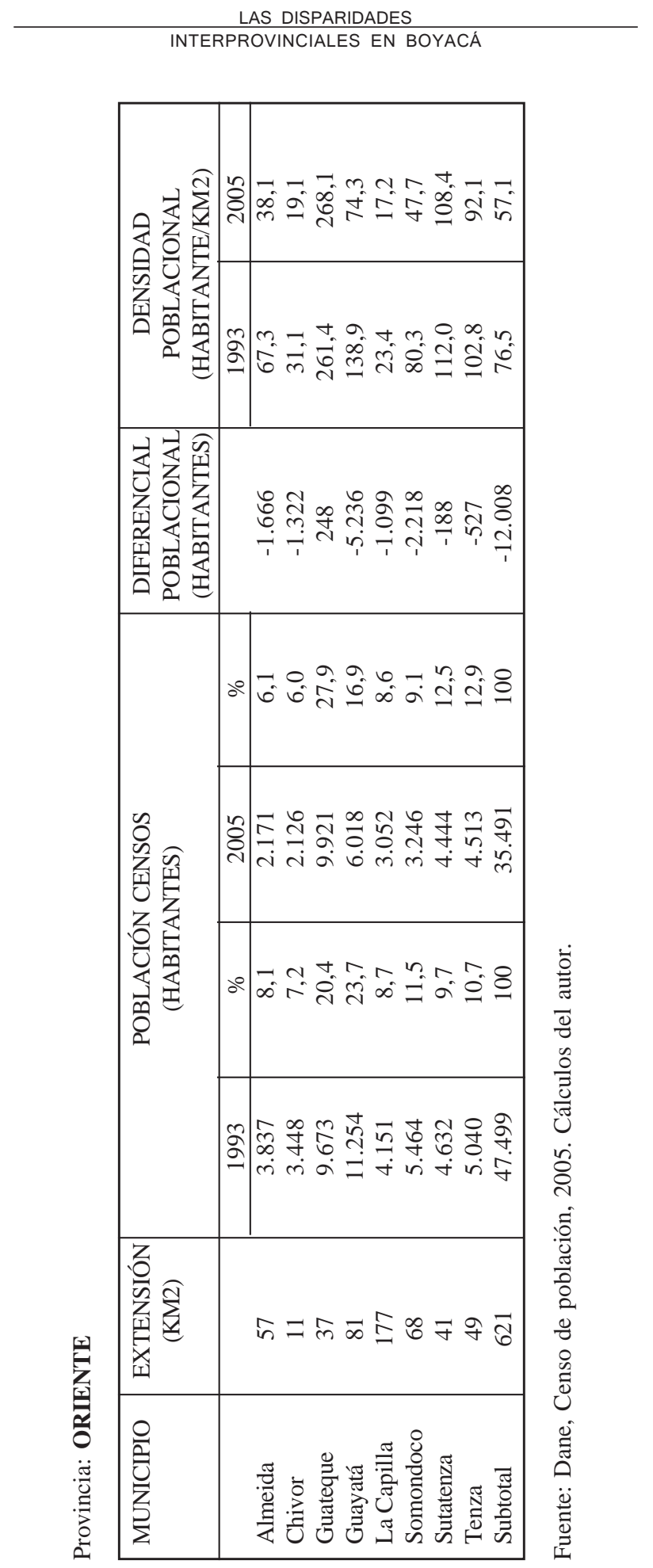




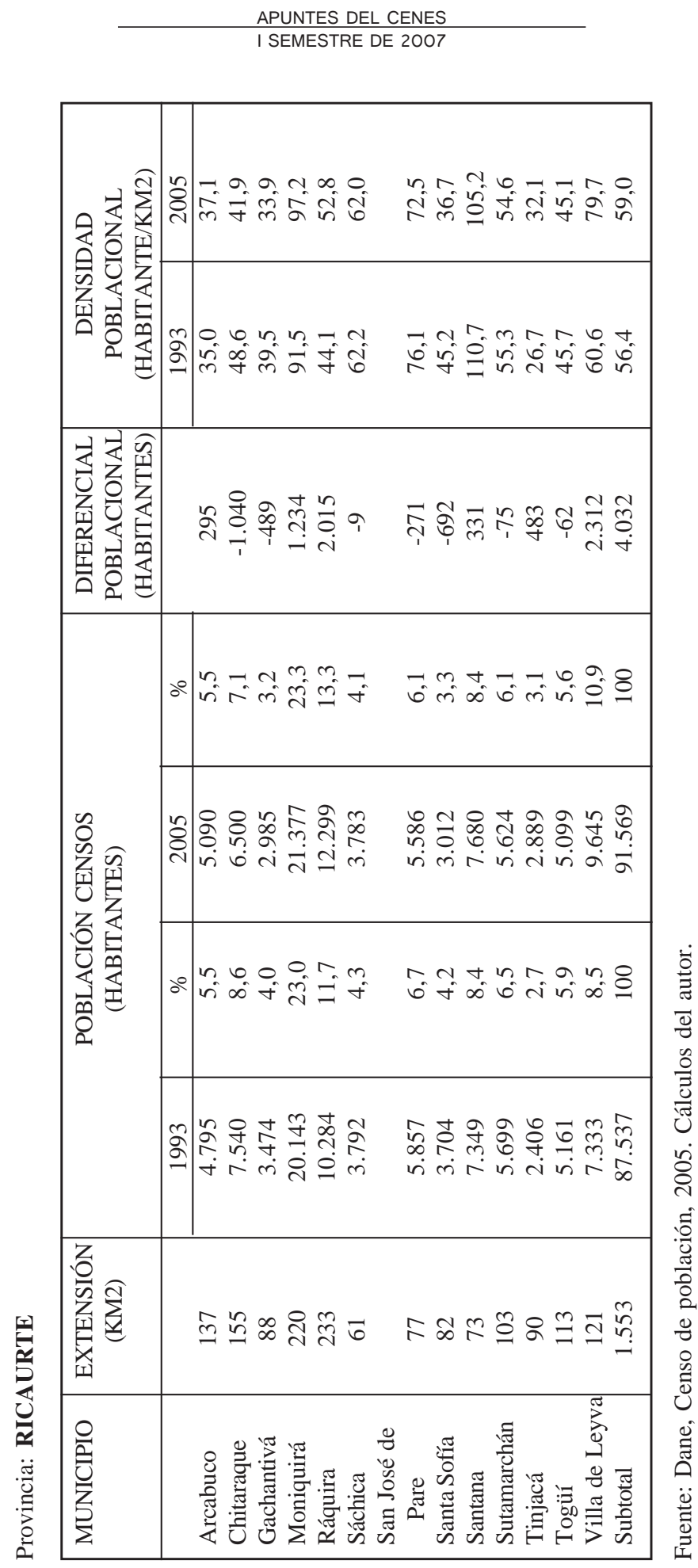




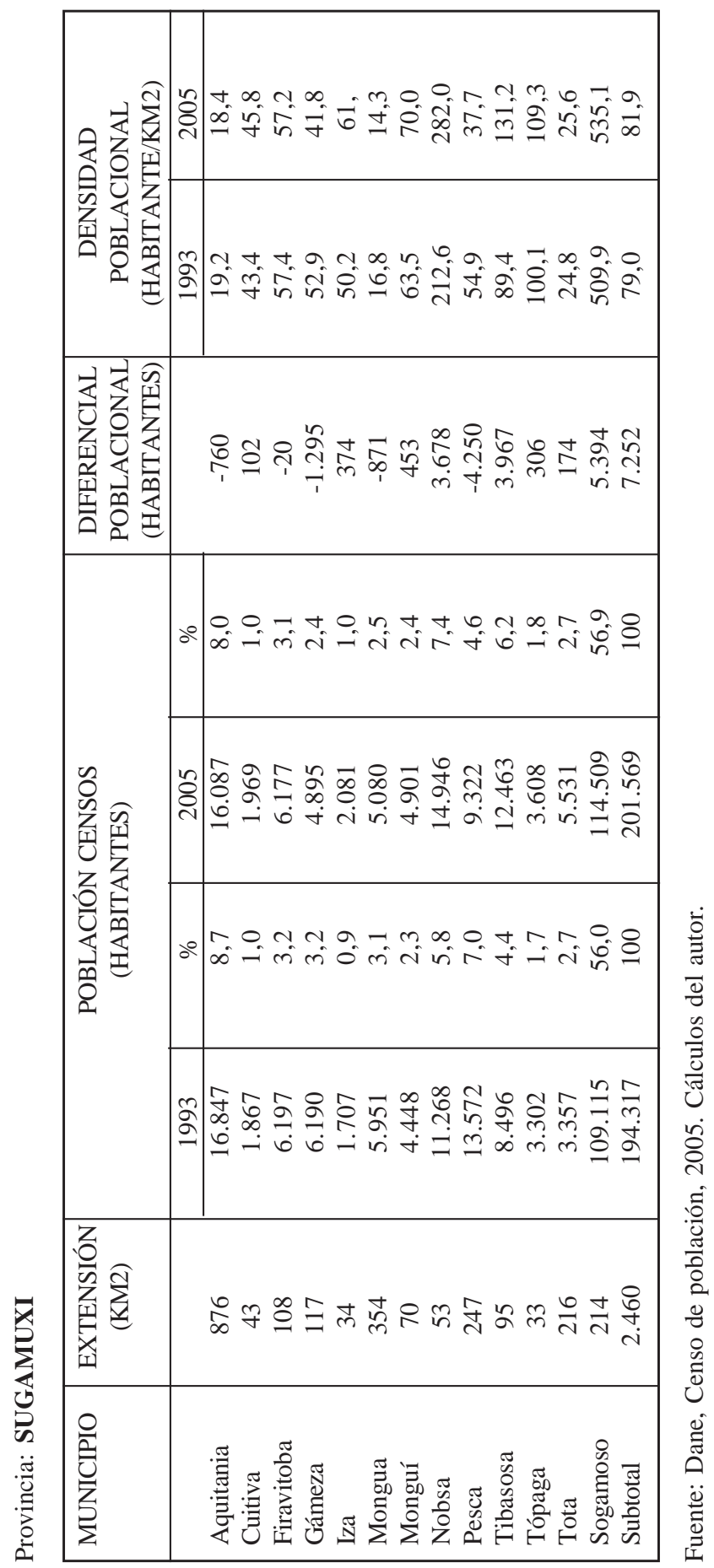




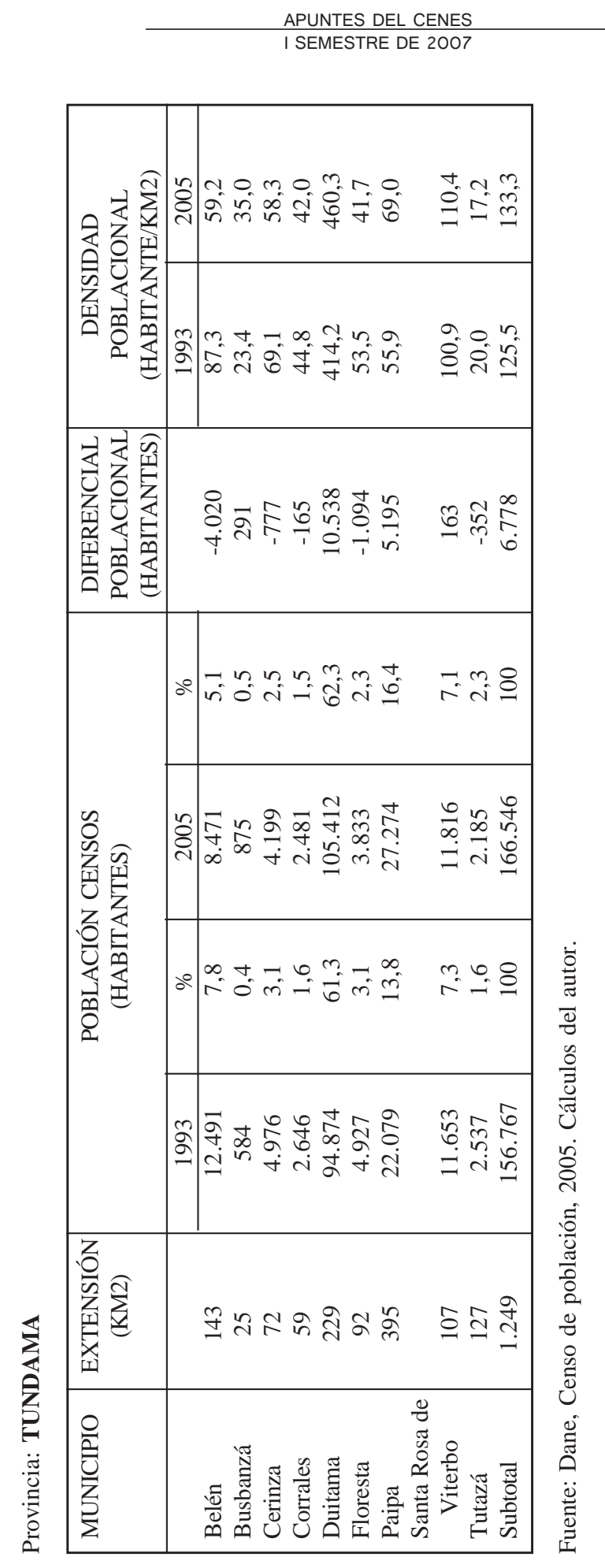




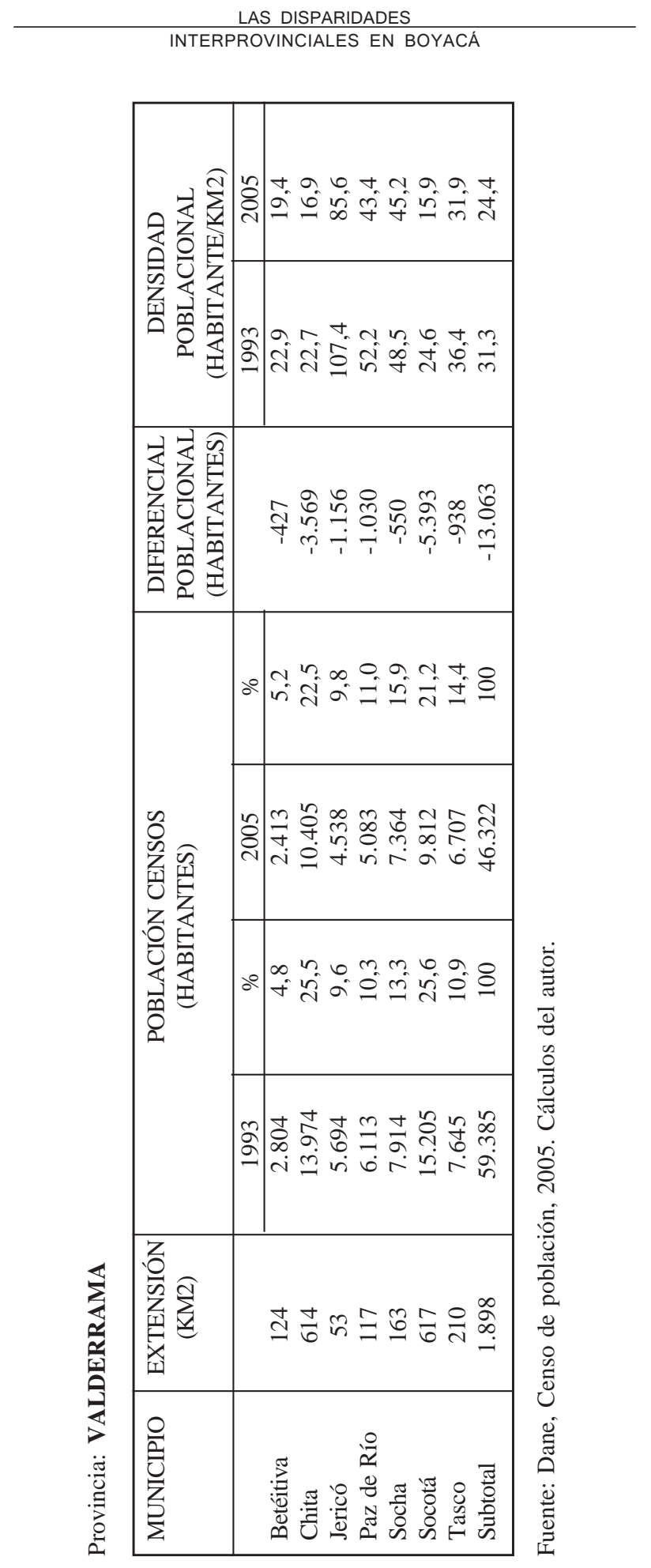




\begin{tabular}{|c|c|c|}
\hline & & $\begin{array}{l}\text { APUNTES DEL CENES } \\
\text { I SEMESTRE DE } 2007\end{array}$ \\
\hline & 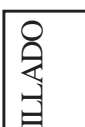 & 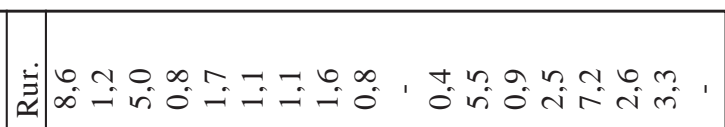 \\
\hline & 悹 & 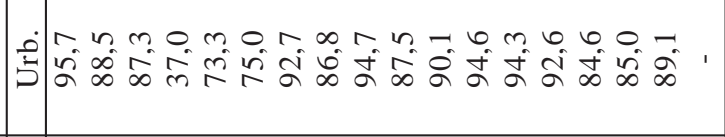 \\
\hline & $\overbrace{1}^{\circ}$ & 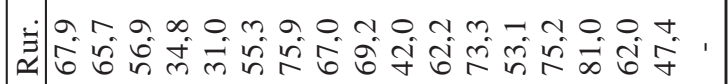 \\
\hline & 至 & 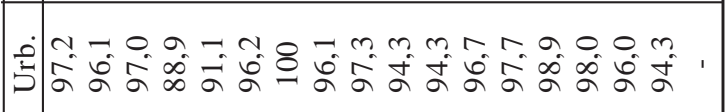 \\
\hline & 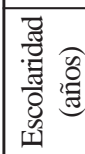 & 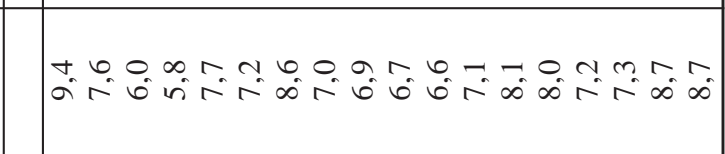 \\
\hline 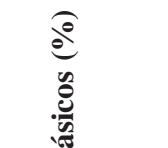 & 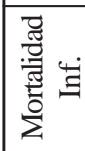 & 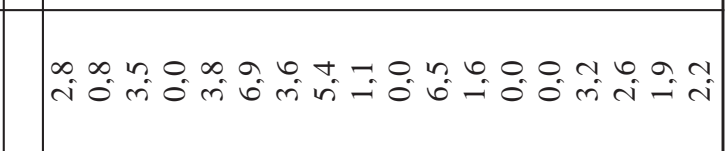 \\
\hline 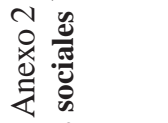 & $: \frac{\pi}{\tilde{g}}$ & 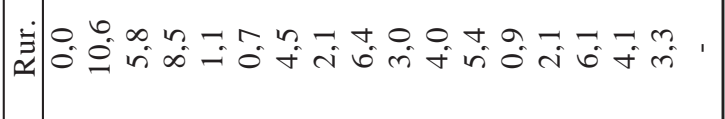 \\
\hline 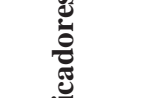 & 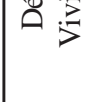 & 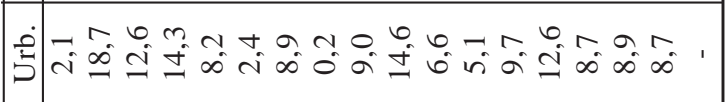 \\
\hline$\Xi$ & 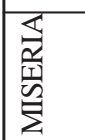 & 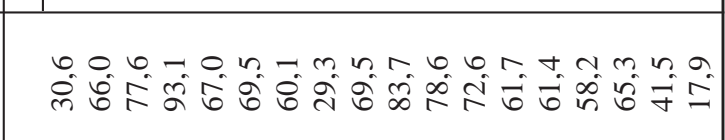 \\
\hline & 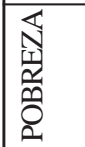 & 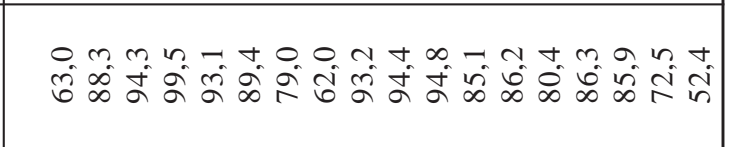 \\
\hline & 己 & 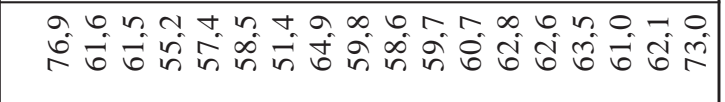 \\
\hline 赵 & $\overline{\mathrm{n}}$ & 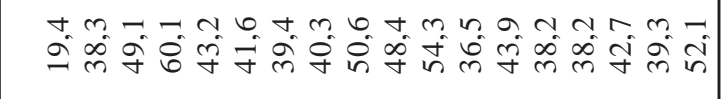 \\
\hline 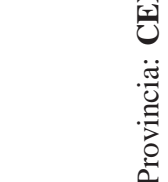 & 帚 & 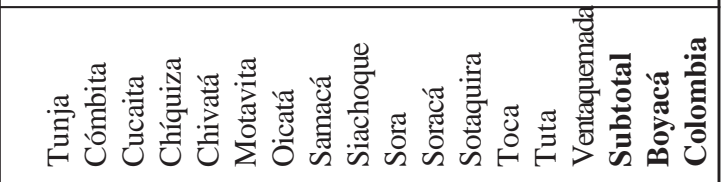 \\
\hline
\end{tabular}




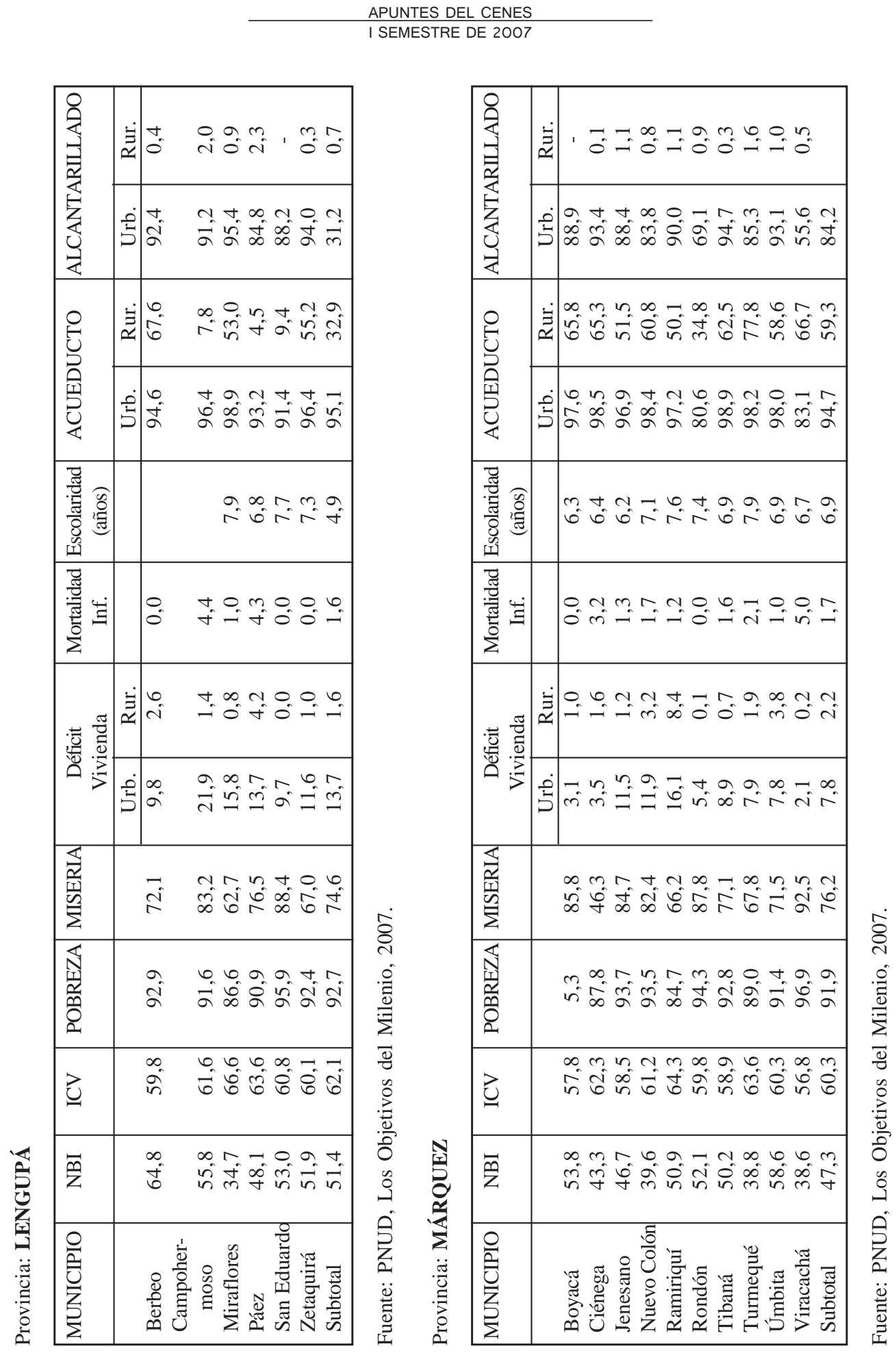




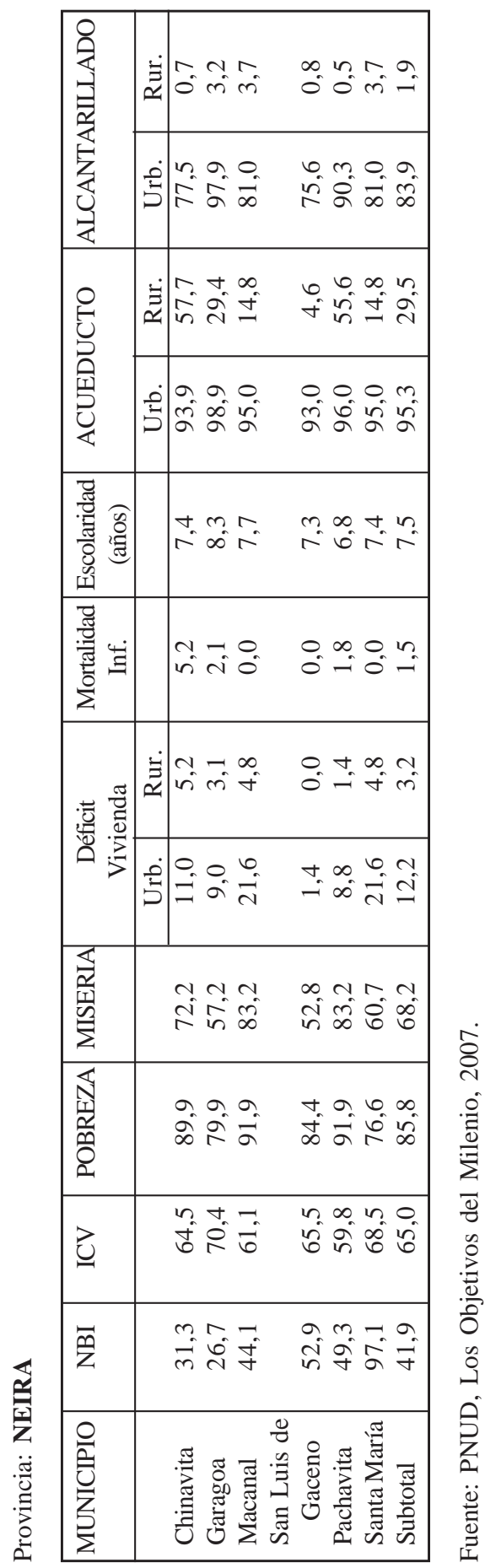

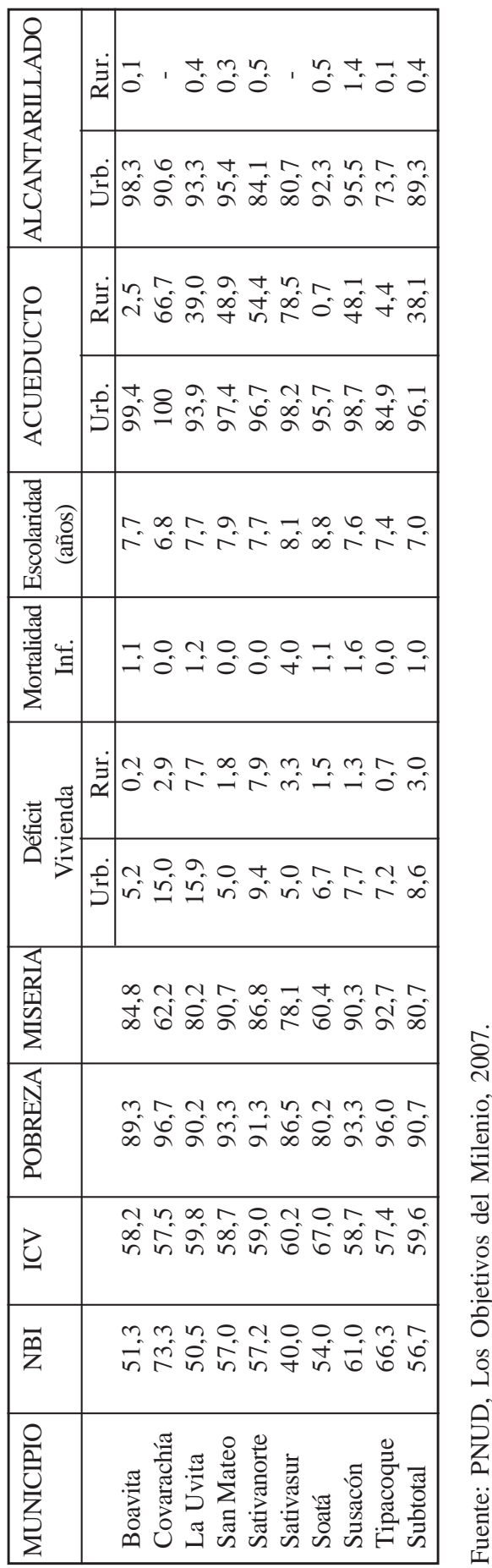




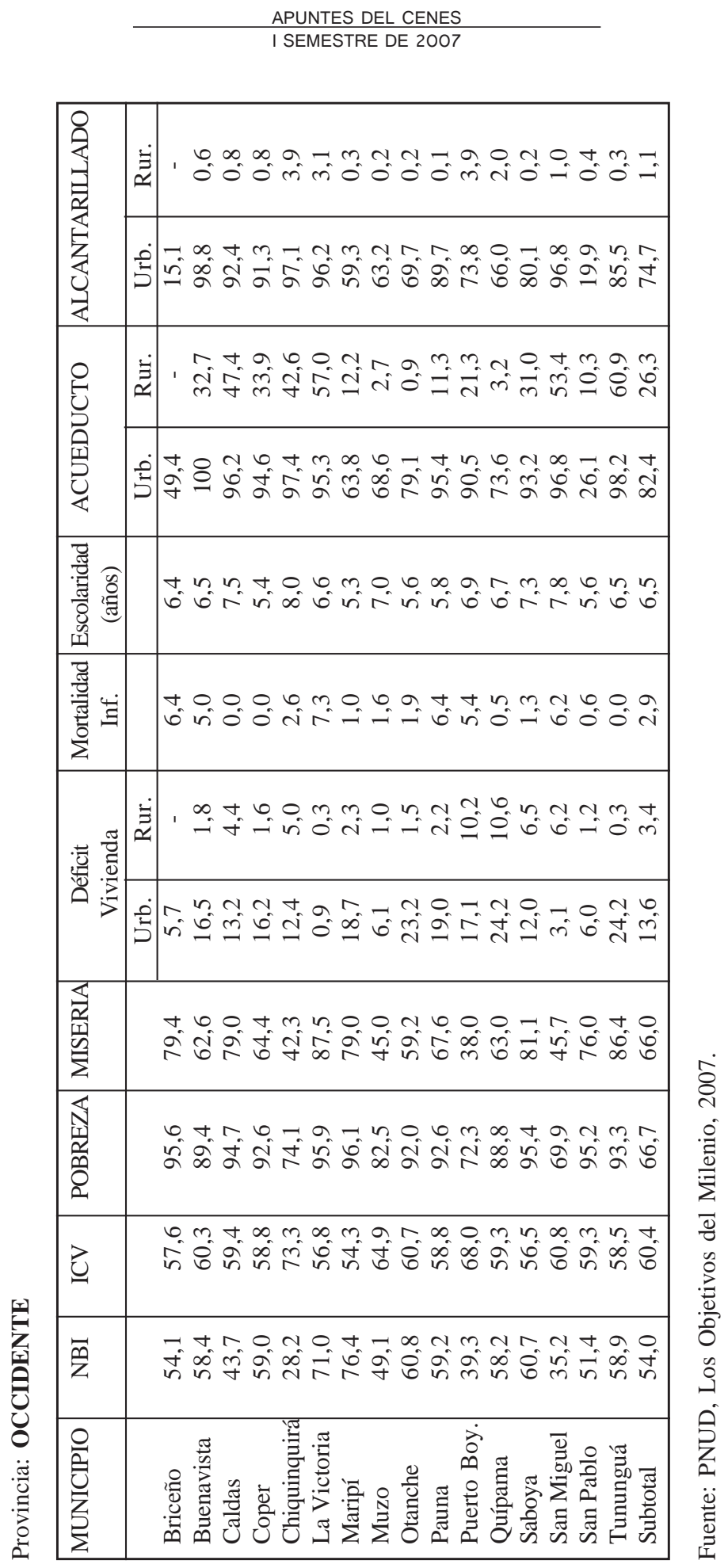




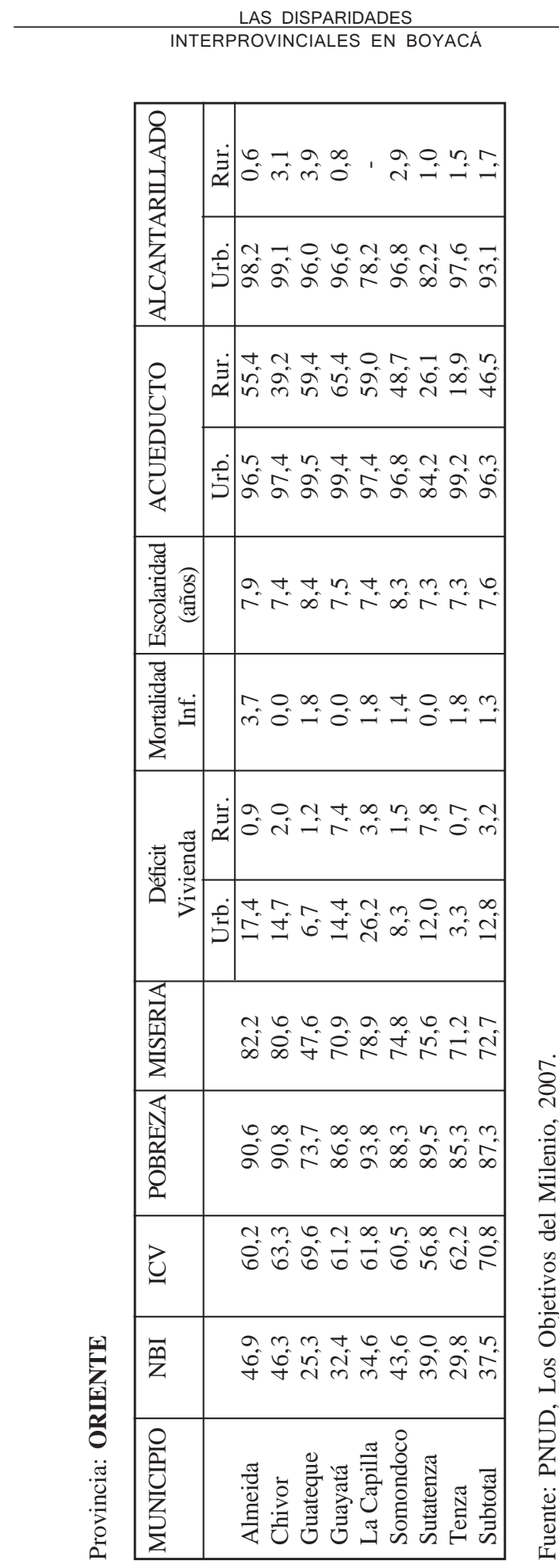




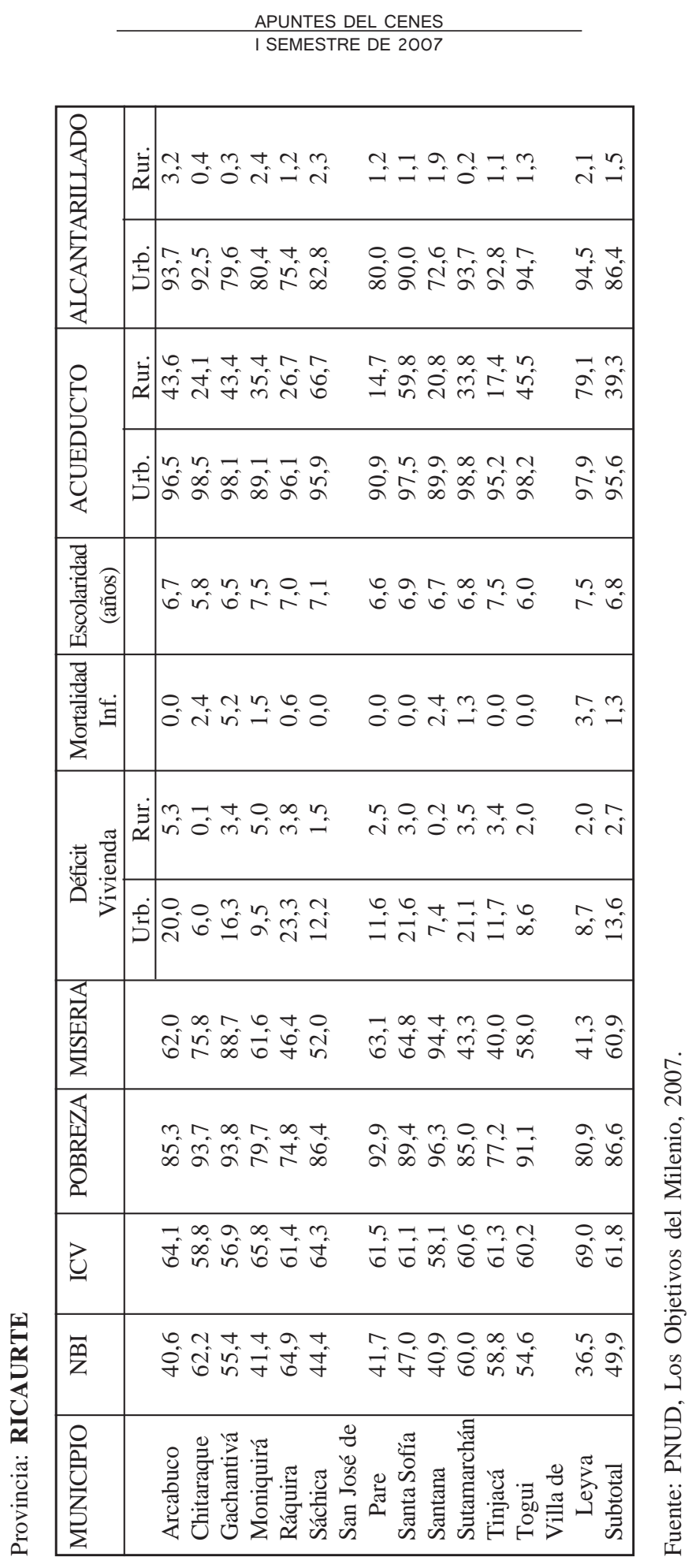




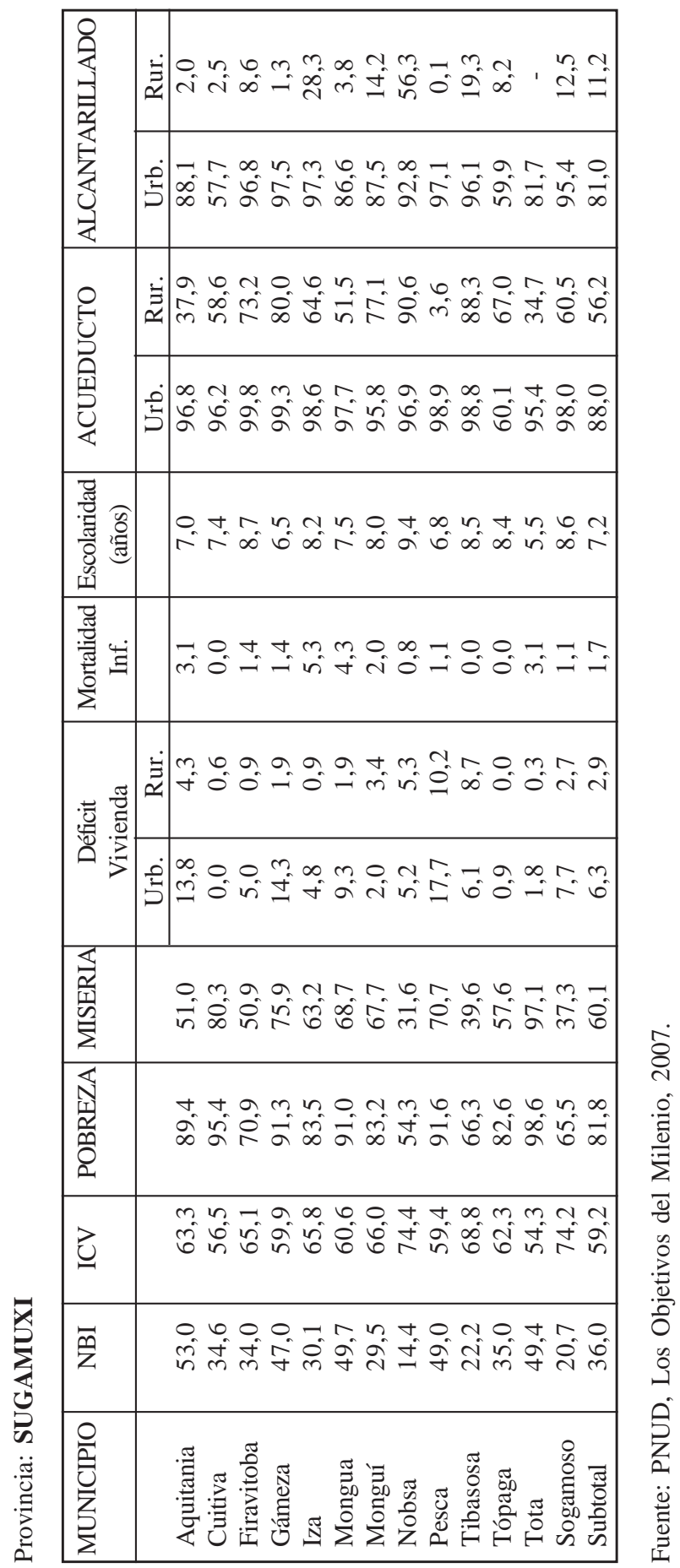




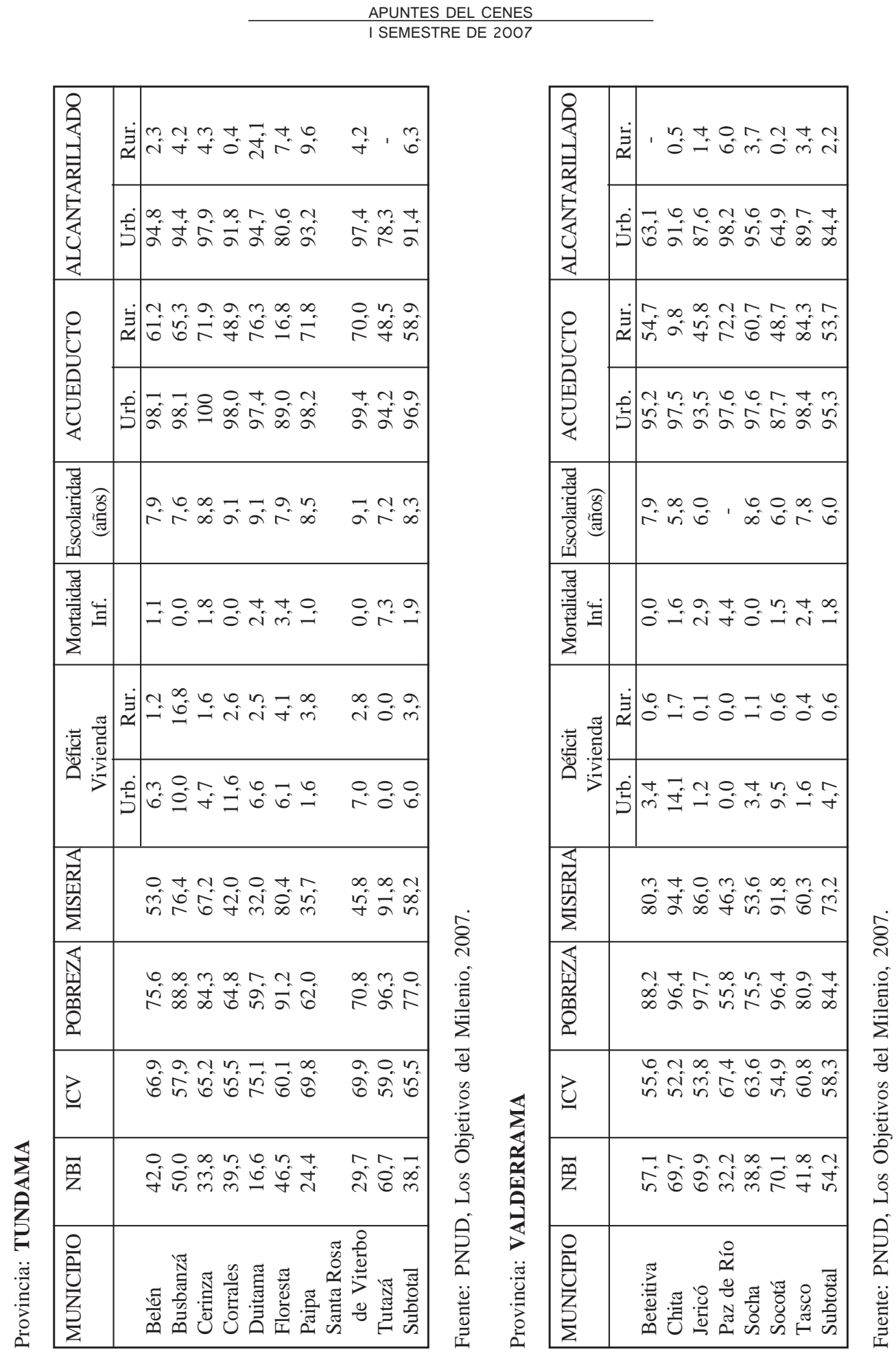




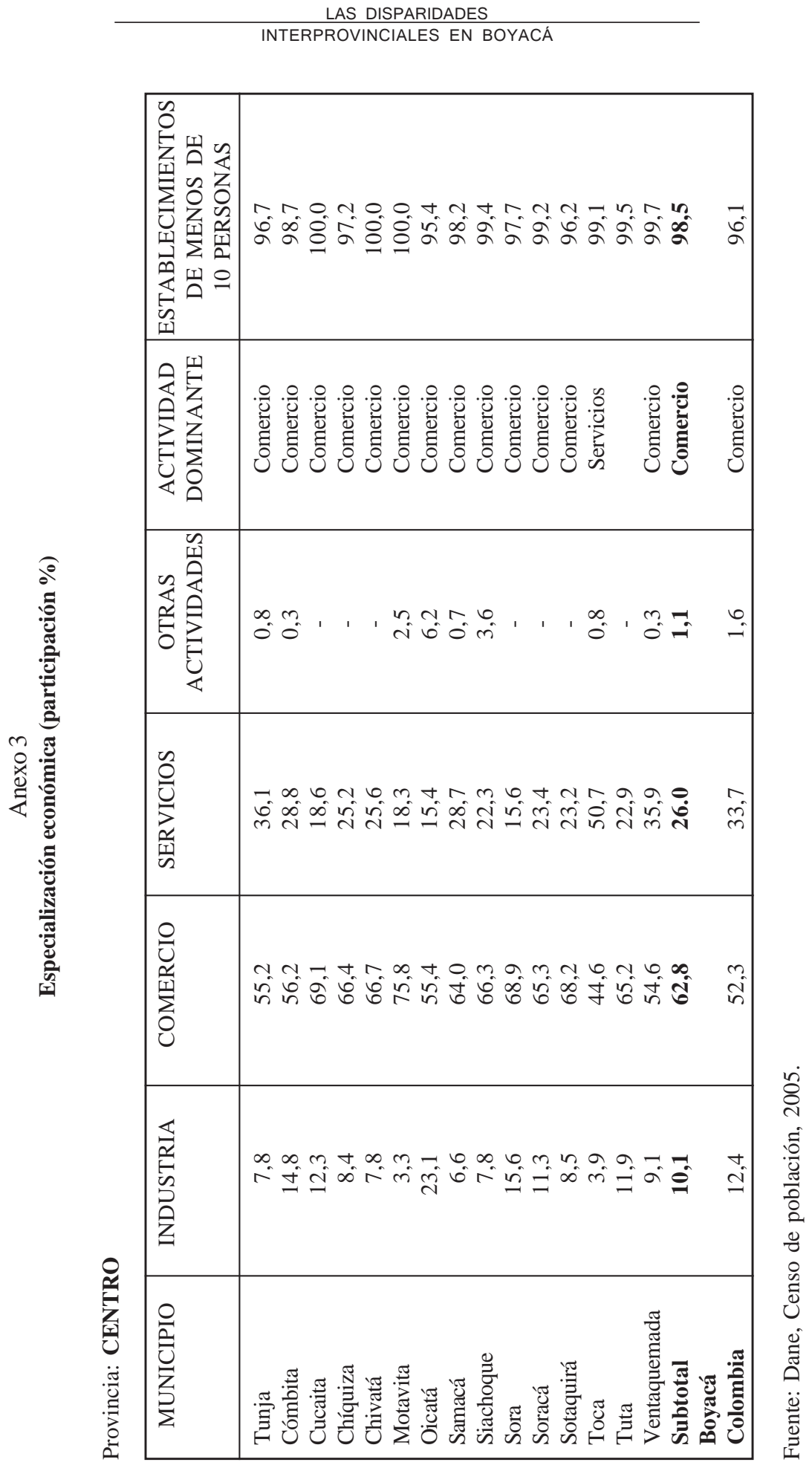




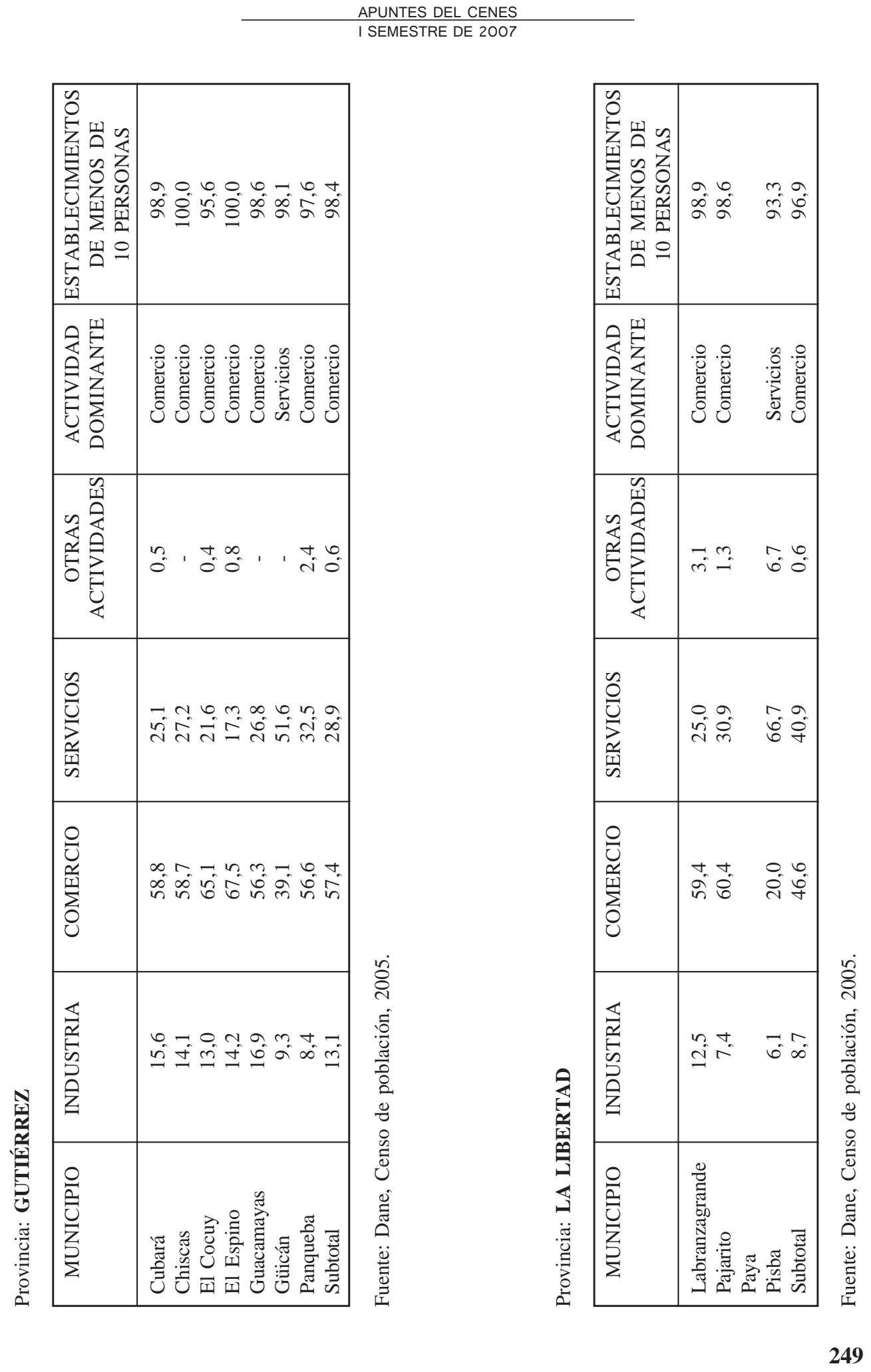




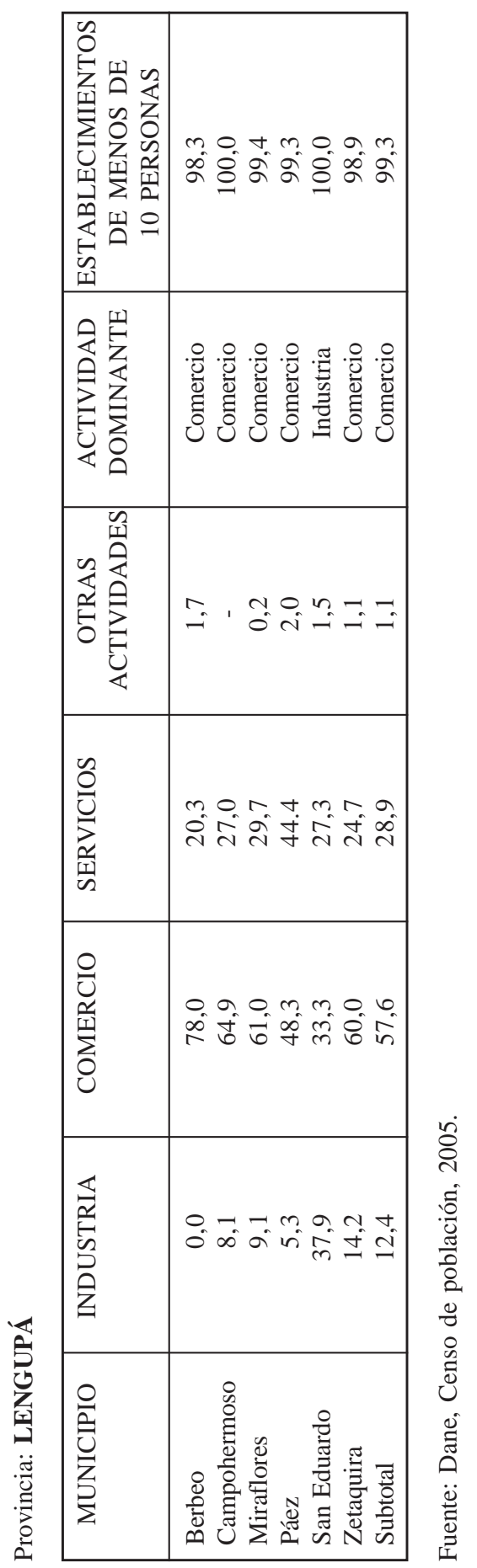

\begin{tabular}{|c|c|c|}
\hline 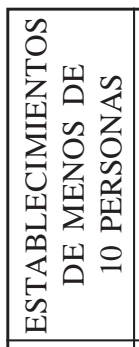 & 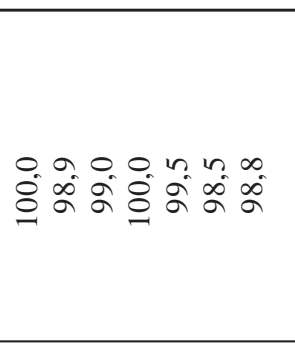 & $\stackrel{+\infty}{\infty} \infty$ \\
\hline 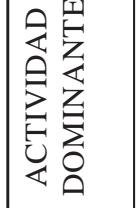 & 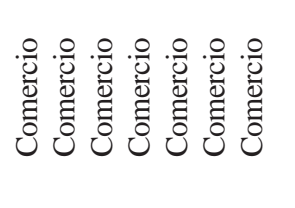 & 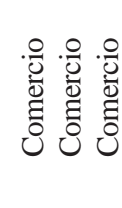 \\
\hline 焉 & 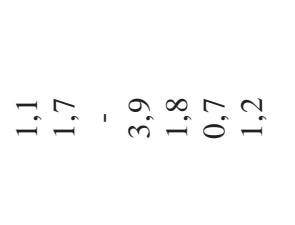 & 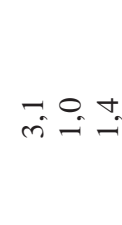 \\
\hline 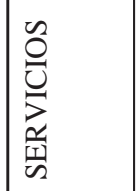 & 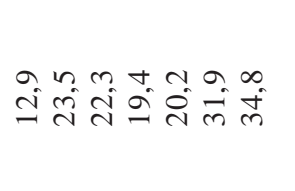 & ते \\
\hline 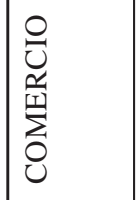 & 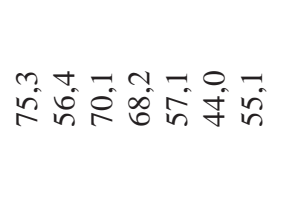 & 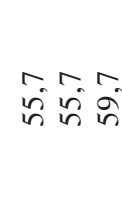 \\
\hline 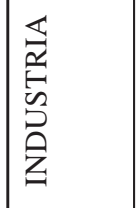 & 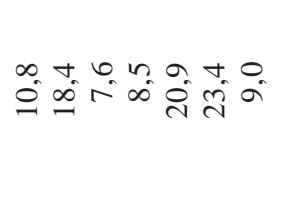 & 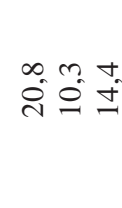 \\
\hline 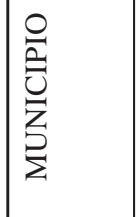 & 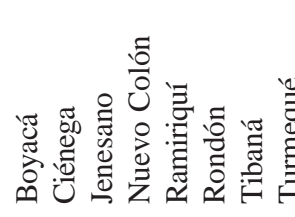 & 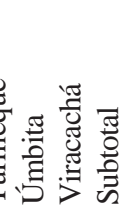 \\
\hline
\end{tabular}

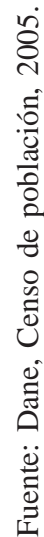




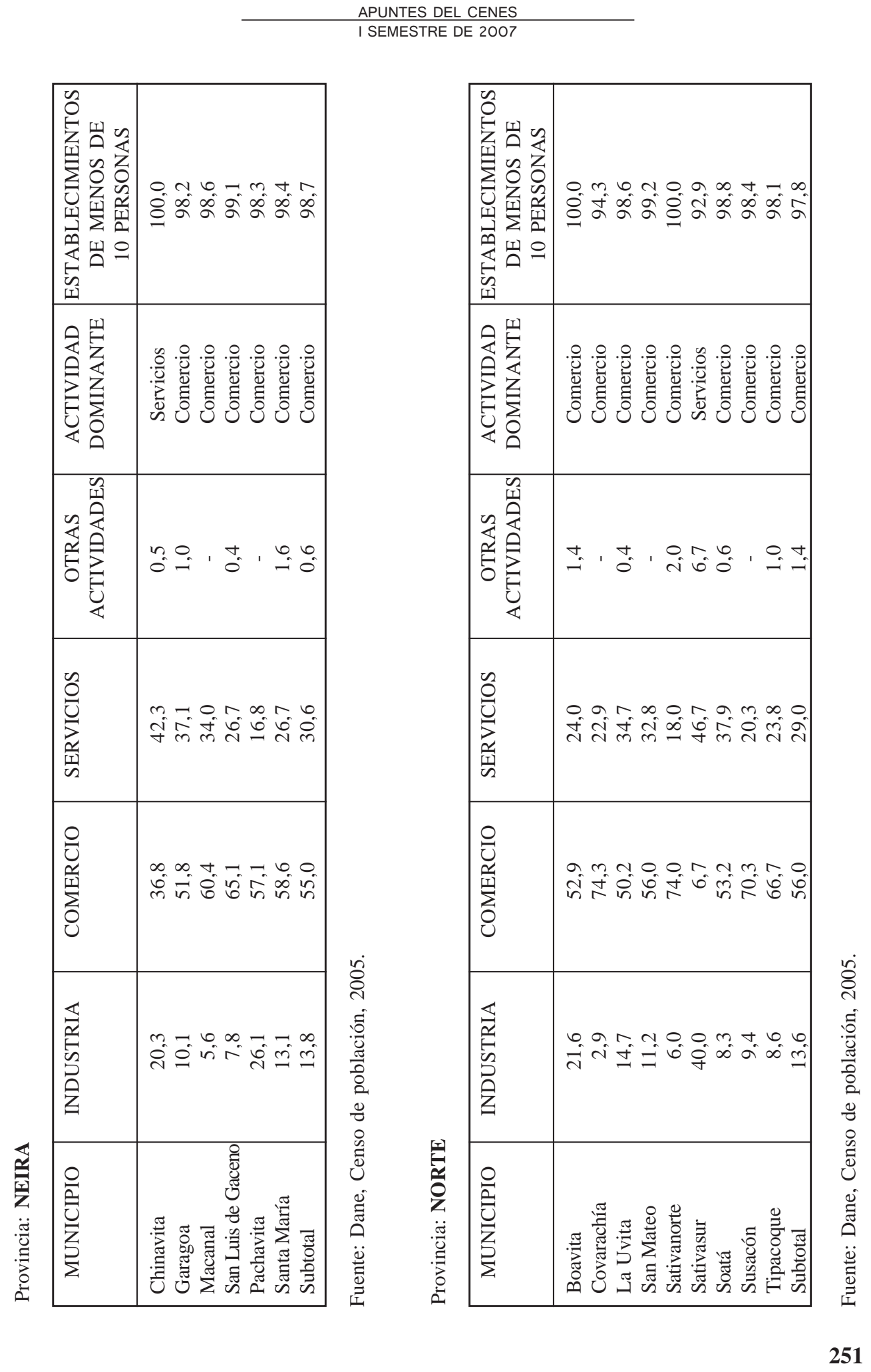




\begin{tabular}{|c|c|}
\hline 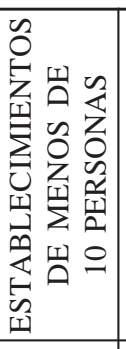 & 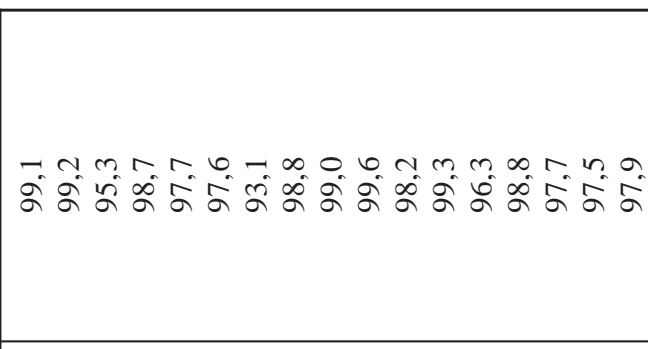 \\
\hline 昆翼 & 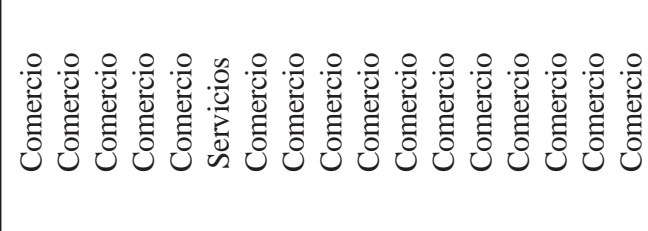 \\
\hline 空 & 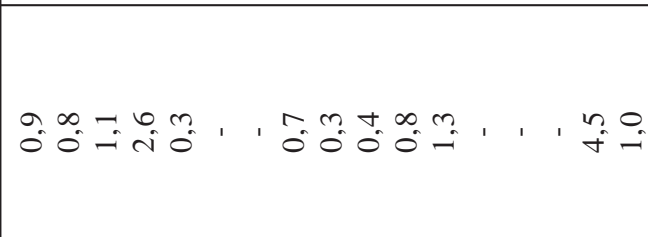 \\
\hline 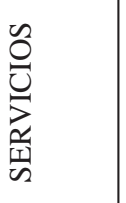 & 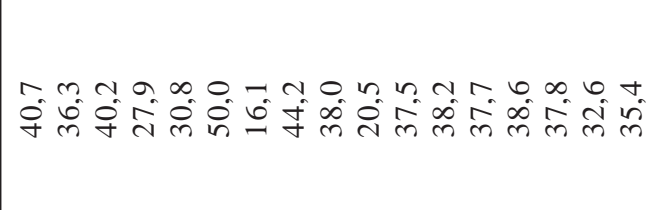 \\
\hline 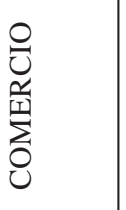 & 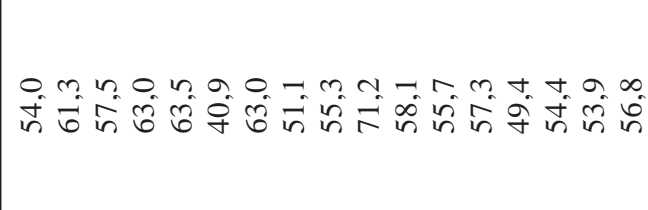 \\
\hline 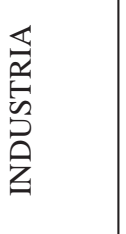 & 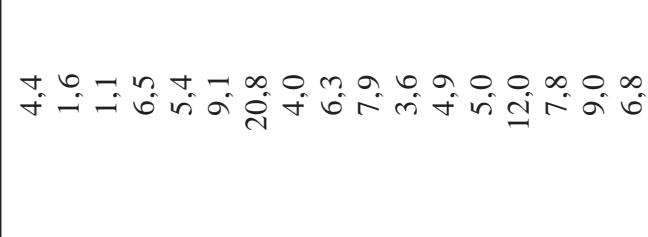 \\
\hline 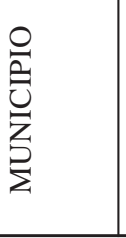 & 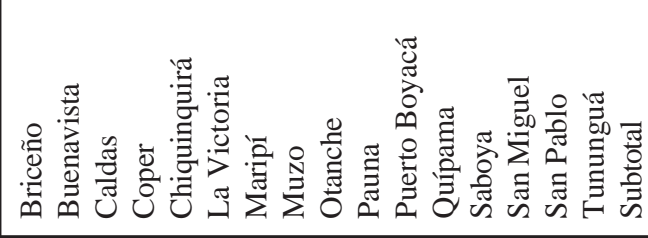 \\
\hline
\end{tabular}




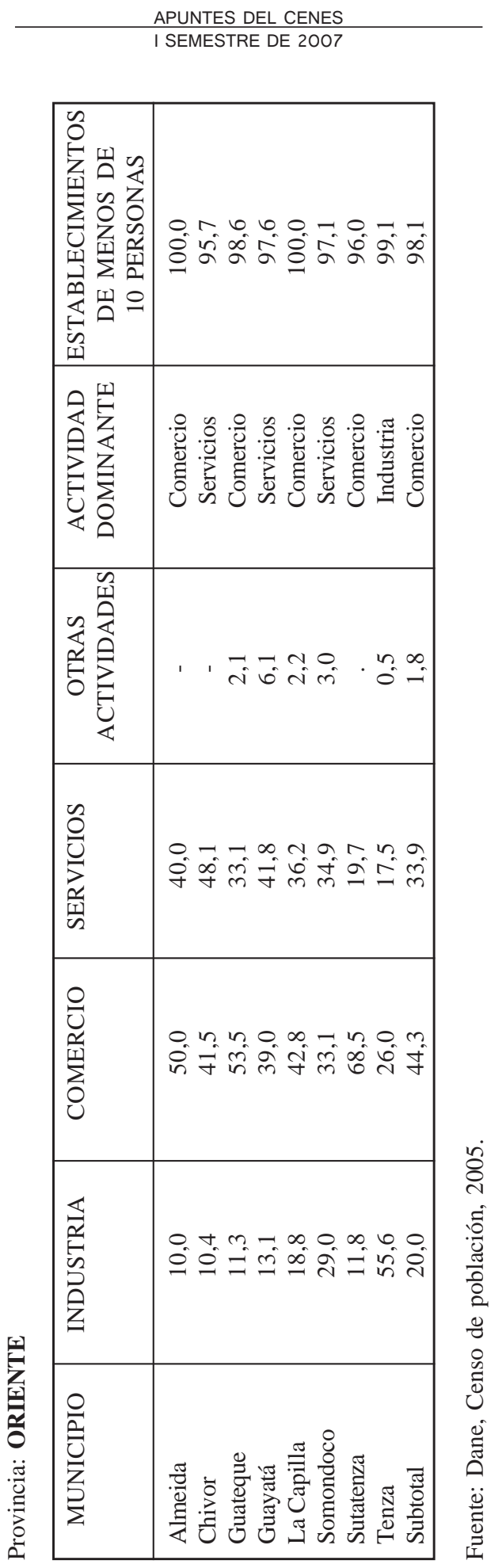




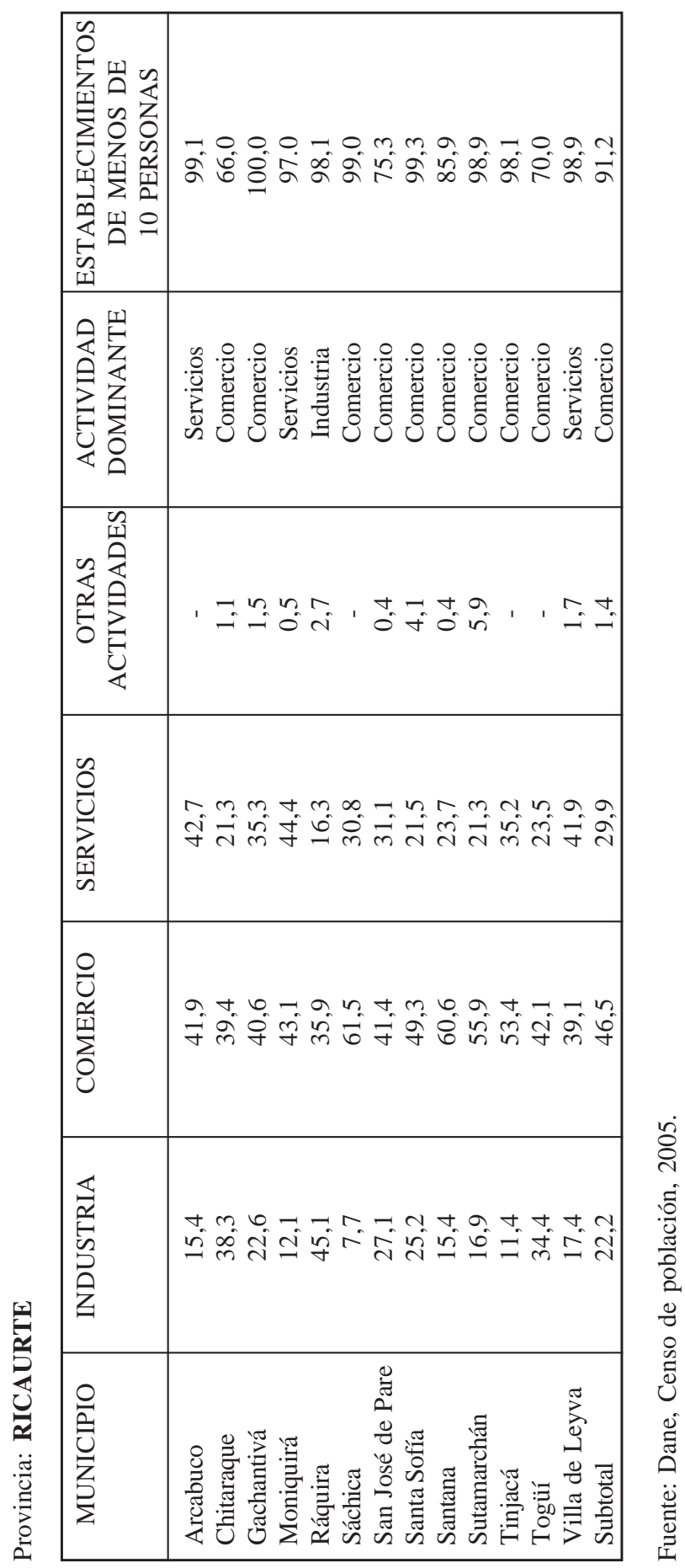




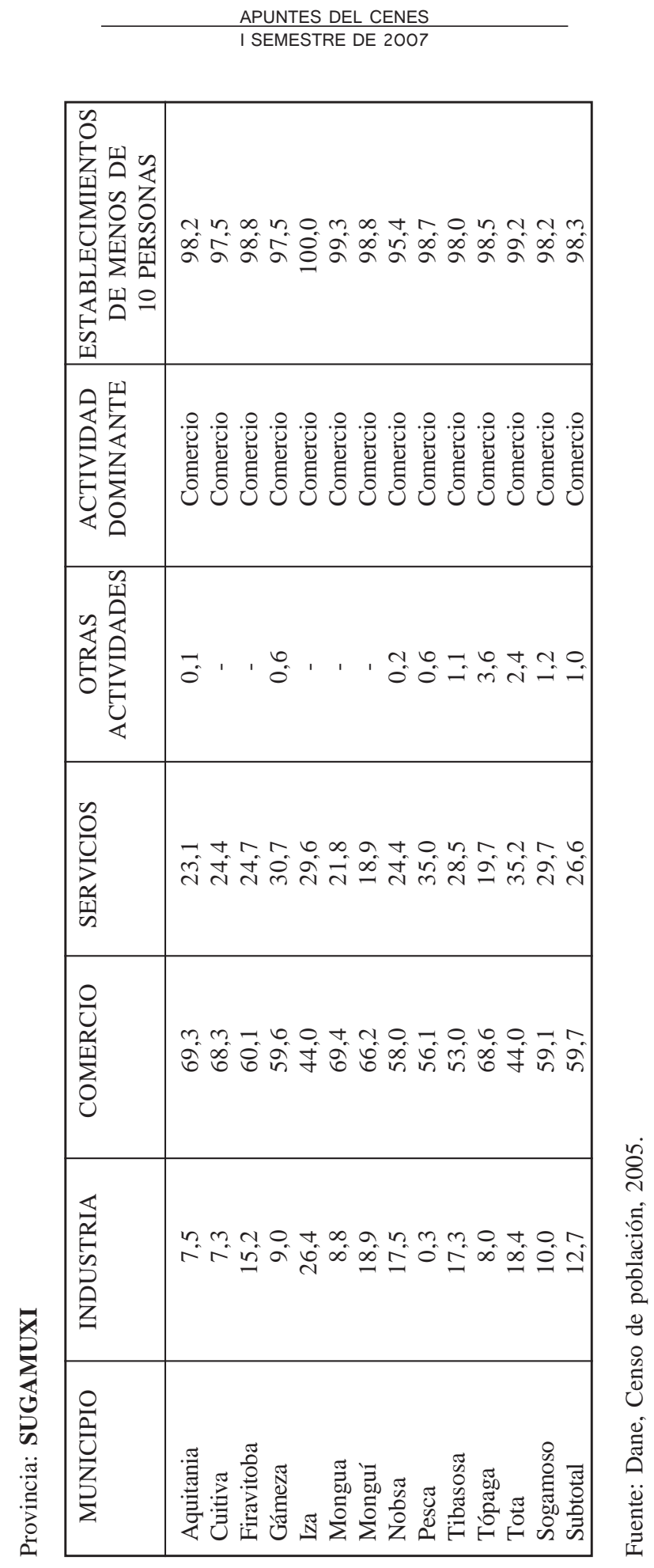



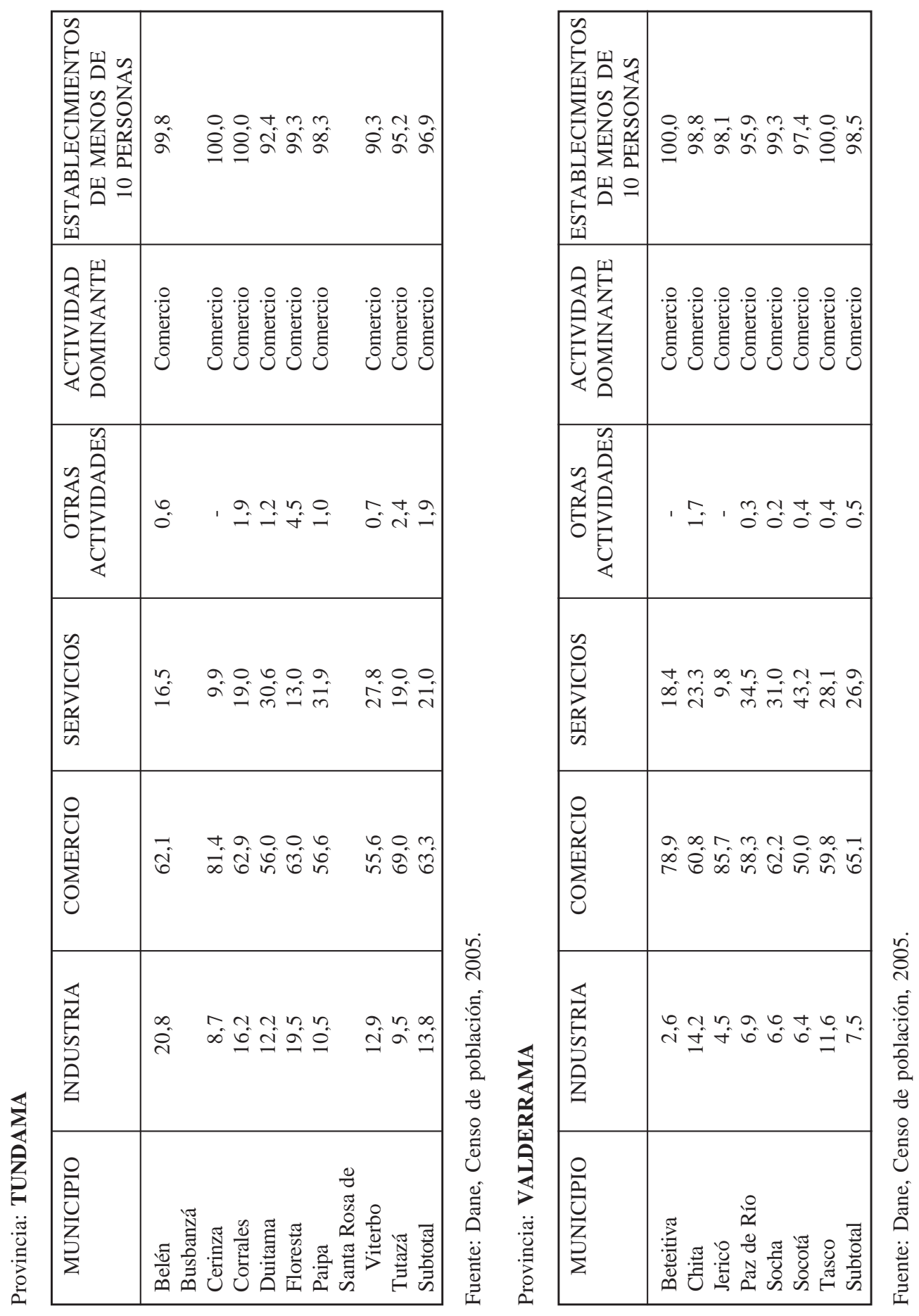